Cochrane Database of Systematic Reviews

\title{
Mechanical assist devices for acute cardiogenic shock (Review)
}

Ni hlci T, Boardman HMP, Baig K, Stafford JL, Cernei C, Bodger O, Westaby S

Ni hlci T, Boardman HMP, Baig K, Stafford JL, Cernei C, Bodger O, Westaby S. Mechanical assist devices for acute cardiogenic shock.

Cochrane Database of Systematic Reviews 2020, Issue 6. Art. No.: CD013002. DOI: 10.1002/14651858.CD013002.pub2.

www.cochranelibrary.com 
TABLE OF CONTENTS

HEADER 1

ABSTRACT

PLAIN LANGUAGE SUMMARY

SUMMARY OF FINDINGS

BACKGROUND

OBJECTIVES

METHODS

RESULTS

Figure 1.

Figure 2.

DISCUSSION

AUTHORS' CONCLUSIONS

ACKNOWLEDGEMENTS

REFERENCES

CHARACTERISTICS OF STUDIES

DATA AND ANALYSES

Analysis 1.1. Comparison 1: Mechanical circulatory support (MCS) versus intra-aortic balloon pump (IABP), Outcome 1: 30-day survival

APPENDICES

HISTORY

CONTRIBUTIONS OF AUTHORS

DECLARATIONS OF INTEREST

SOURCES OF SUPPORT

DIFFERENCES BETWEEN PROTOCOL AND REVIEW 
[Intervention Review]

\section{Mechanical assist devices for acute cardiogenic shock}

Tamara Ni hlci ${ }^{1}$, Henry MP Boardman², Kamran Baig ${ }^{3}$, Jody L Stafford ${ }^{4}$, Cristina Cernei ${ }^{5}$, Owen Bodger ${ }^{5}$, Stephen Westaby ${ }^{6}$

${ }^{1}$ Cardiothoracic Surgery, Morriston Hospital, Swansea, UK. 2Radcliffe Department of Medicine, John Radcliffe Hospital, Oxford University Hospitals NHS Foundation Trust, Oxford, UK. 'Department of Cardiac Surgery, Guy's and St Thomas' NHS Foundation Trust, London, UK. ${ }^{4}$ Perfusion/Cardiothoracic Surgery, University Hospital of Wales, Cardiff, UK. 5 Swansea University Medical School, Swansea University, Swansea, UK. ${ }^{6}$ Cardiothoracic Surgery, John Radcliffe Hospital, Oxford University Hospitals NHS Foundation Trust, Oxford, UK

Contact address: Tamara Ni hlci, tamaranihici@gmail.com, tamaranihici@wales.nhs.uk.

Editorial group: Cochrane Heart Group.

Publication status and date: New, published in Issue 6, 2020.

Citation: Ni hlci T, Boardman HMP, Baig K, Stafford JL, Cernei C, Bodger O, Westaby S. Mechanical assist devices for acute cardiogenic shock. Cochrane Database of Systematic Reviews 2020, Issue 6. Art. No.: CD013002. DOI: 10.1002/14651858.CD013002.pub2.

Copyright @ 2020 The Cochrane Collaboration. Published by John Wiley \& Sons, Ltd.

\section{A B S T R A C T}

\section{Background}

Cardiogenic shock (CS) is a state of critical end-organ hypoperfusion due to a primary cardiac disorder. For people with refractory CS despite maximal vasopressors, inotropic support and intra-aortic balloon pump, mortality approaches $100 \%$. Mechanical assist devices provide mechanical circulatory support (MCS) which has the ability to maintain vital organ perfusion, to unload the failing ventricle thus reduce intracardiac filling pressures which reduces pulmonary congestion, myocardial wall stress and myocardial oxygen consumption. This has been hypothesised to allow time for myocardial recovery (bridge to recovery) or allow time to come to a decision as to whether the person is a candidate for a longer-term ventricular assist device (VAD) either as a bridge to heart transplantation or as a destination therapy with a long-term VAD.

\section{Objectives}

To assess whether mechanical assist devices improve survival in people with acute cardiogenic shock.

\section{Search methods}

We searched CENTRAL, MEDLINE (Ovid), Embase (Ovid) and Web of Science Core Collection in November 2019. In addition, we searched three trials registers in August 2019. We scanned reference lists and contacted experts in the field to obtain further information. There were no language restrictions.

\section{Selection criteria}

Randomised controlled trials on people with acute CS comparing mechanical assist devices with best current intensive care management, including intra-aortic balloon pump and inotropic support.

\section{Data collection and analysis}

We performed data collection and analysis according to the published protocol.

Primary outcomes were survival to discharge, 30 days, 1 year and secondary outcomes included, quality of life, major adverse cardiovascular events (30 days/end of follow-up), dialysis-dependent (30 days/end of follow-up), length of hospital stay and length of intensive care unit stay and major adverse events.

We used the five GRADE considerations (study limitations, consistency of effect, imprecision, indirectness, and publication bias) to assess the quality of a body of evidence as it relates to the studies which contribute data to the meta-analyses for the prespecified outcomes 
Summary statistics for the primary endpoints were risk ratios (RR), hazard ratios (HRs) and odds ratios (ORs) with 95\% confidence intervals (Cls).

\section{Main results}

The search identified five studies from 4534 original citations reviewed. Two studies included acute CS of all causes randomised to treatment using TandemHeart percutaneous VAD and three studies included people with CS secondary to acute myocardial infarction who were randomised to Impella CP or best medical management. Meta-analysis was performed only to assess the 30-day survival as there were insufficient data to perform any further meta-analyses. The results from the five studies with 162 participants showed mechanical assist devices may have little or no effect on 30-day survival (RR of $1.0195 \% \mathrm{Cl} 0.76$ to 1.35 ) but the evidence is very uncertain.

Complications such as sepsis, thromboembolic phenomena, bleeding and major adverse cardiovascular events were not infrequent in both the MAD and control group across the studies, but these could not be pooled due to inconsistencies in adverse event definitions and reporting.

We identified four randomised control trials assessing mechanical assist devices in acute CS that are currently ongoing.

\section{Authors' conclusions}

There is no evidence from this review of a benefit from MCS in improving survival for people with acute CS. Further use of the technology, risk stratification and optimising the use protocols have been highlighted as potential reasons for lack of benefit and are being addressed in the current ongoing clinical trials.

\section{PLAIN LANGUAGE SUMMARY}

\section{Mechanical heart pumps to aid a heart that fails suddenly}

\section{Background}

Conditions that prevent the heart pumping effectively remain the leading cause of death globally. A heart attack is the most common condition that causes the heart pump to fail (called cardiogenic shock), but other causes exist such as viral infections, heart valve disease and problems with the muscle. When the heart muscle has been damaged so extensively that it can no longer pump effectively function has to be improved or organ damage and death will occur. Even with the best treatments that we currently have, the risk of dying is extremely high. Mechanical assist devices that can help the heart to pump more effectively have been developed so that the heart can recover from the insult.

However, the evidence for these treatments is scare and the aim of this review is to assess if these devices do help more people to survive. We assessed randomised control trials (clinical studies where people are randomly put into one of two or more treatment groups) where these devices were used and compare the outcome of these people to those who did not receive a device and received best medical treatment (with medicines to help the heart to pump).

\section{Results}

The evidence is current to 25 November 2019.

We identified five trials that enrolled 162 people in shock due to their heart failing. These people were randomised to using mechanical assist devices with current best management practice or current best medical management alone (which includes medicines to help the heart to pump more effectively).

The quality of the evidence was very low, due to difficulties in accounting for biases (one cannot hide the fact that a person receives a mechanical assist device, difficulty in enrolling participants, gaining consent when a person is very close to dying, and variations in the protocols on the timing of the devices and the types of devices used).

From the data, there was little or no effect on survival at 30 days if a device was used alongside current best medical management or current best medical management alone. However, we are uncertain about these findings.

Complications such as sepsis, thromboembolic phenomena, bleeding and major adverse cardiovascular events were not infrequent in both the MAD and control group across the studies, but these could not be pooled due to inconsistencies in adverse event definitions and reporting.

Currently there are four ongoing trials. They are assessing if they can improve outcomes by selecting the people who would most likely have a benefit.

\section{Conclusions}


In conclusion, this review was unable to assess if mechanical assist devices help people with cardiogenic shock due to their heart failing. We await the results of the ongoing trials, which we anticipate will help clarify whether these devices will help people to survive with a full recovery or not. 
SUMMARY OF FINDINGS

\section{Summary of findings 1. Mechanical assist devices compared to intra-aortic balloon pump for acute cardiogenic shock at 30-day follow-up}

MAD compared to IABP for acute cardiogenic shock 30-day follow-up

Patient or population: people with acute cardiogenic shock

Setting: hospital or intensive care unit

Intervention: $M A D$

Comparison: IABP

\begin{tabular}{|c|c|c|c|c|c|c|}
\hline \multirow[t]{2}{*}{$\begin{array}{l}\text { Out- } \\
\text { comes }\end{array}$} & \multicolumn{2}{|c|}{$\begin{array}{l}\text { Anticipated ab- } \\
\text { solute effects }{ }^{\star}(95 \% \\
\text { CI) }\end{array}$} & \multirow[t]{2}{*}{$\begin{array}{l}\text { Relative } \\
\text { effect } \\
(95 \% \mathrm{CI})\end{array}$} & \multirow{2}{*}{$\begin{array}{l}\text { № of } \\
\text { partic- } \\
\text { ipants } \\
\text { (stud- } \\
\text { ies) }\end{array}$} & \multirow{2}{*}{$\begin{array}{l}\text { Certain- } \\
\text { ty of } \\
\text { the evi- } \\
\text { dence } \\
\text { (GRADE) }\end{array}$} & \multirow[t]{2}{*}{ Comments } \\
\hline & $\begin{array}{l}\text { Risk } \\
\text { with } \\
\text { IABP }\end{array}$ & $\begin{array}{l}\text { Risk } \\
\text { with } \\
\text { MAD }\end{array}$ & & & & \\
\hline $\begin{array}{l}\text { 30-day } \\
\text { survival }\end{array}$ & \multicolumn{2}{|c|}{ Study population } & \multirow{2}{*}{$\begin{array}{l}\text { RR 1.01 } \\
(0.76 \text { to } \\
1.35)\end{array}$} & \multirow{2}{*}{$\begin{array}{l}162 \\
\text { (5 RCTs) }\end{array}$} & \multirow{2}{*}{$\begin{array}{l}\oplus \odot \Theta \Theta \\
\text { Very low } \\
\text { a,b }\end{array}$} & \multirow[t]{2}{*}{-} \\
\hline $\begin{array}{l}\text { Fol- } \\
\text { low-up } \\
\text { of } 30 \\
\text { days was } \\
\text { com- } \\
\text { plete } \\
\text { in all } 5 \\
\text { studies. }\end{array}$ & $\begin{array}{l}542 \text { per } \\
1000\end{array}$ & $\begin{array}{l}536 \text { per } \\
1000 \\
(395 \text { to } \\
715)\end{array}$ & & & & \\
\hline $\begin{array}{l}\text { Quality } \\
\text { of life }\end{array}$ & \multicolumn{6}{|c|}{ No study described quality of life. } \\
\hline MACE & - & & & $\begin{array}{l}122 \\
\text { (3 RCTs) }\end{array}$ & $\begin{array}{l}\oplus \odot \Theta \odot \\
\text { Very low } \\
\text { a,b }\end{array}$ & $\begin{array}{l}3 \text { studies described MACE events in a very heterogeneous manner without any clear definitions } \\
\text { in any of the studies (Ouweneel 2017; Seyfarth 2008; Thiele 2005). CVA occurred in } 1 \text { participant } \\
\text { who had a MAD and } 1 \text { participant who had IABP only (both in Ouweneel } 2017 \text { and both CVA were } \\
\text { ischaemic). Ouweneel } 2017 \text { was the only study to describe if any cases had myocardial reinfarction } \\
\text { reporting that this occurred in } 1 \text { participant who had MAD and } 2 \text { participants who had IABP only. } \\
\text { Ouweneel } 2017 \text { described that } 1 \text { participant had a major vascular complication, with a retroperi- } \\
\text { toneal bleed after percutaneous MAD insertion. Thiele } 2005 \text { described that } 7 \text { participants devel- } \\
\text { oped limb ischaemia following insertion of a 17-French arterial cannula. Limb ischaemia could be } \\
\text { resolved by surgical approach in } 3 \text { participants and by percutaneous approach in } 4 \text { participants. }\end{array}$ \\
\hline
\end{tabular}




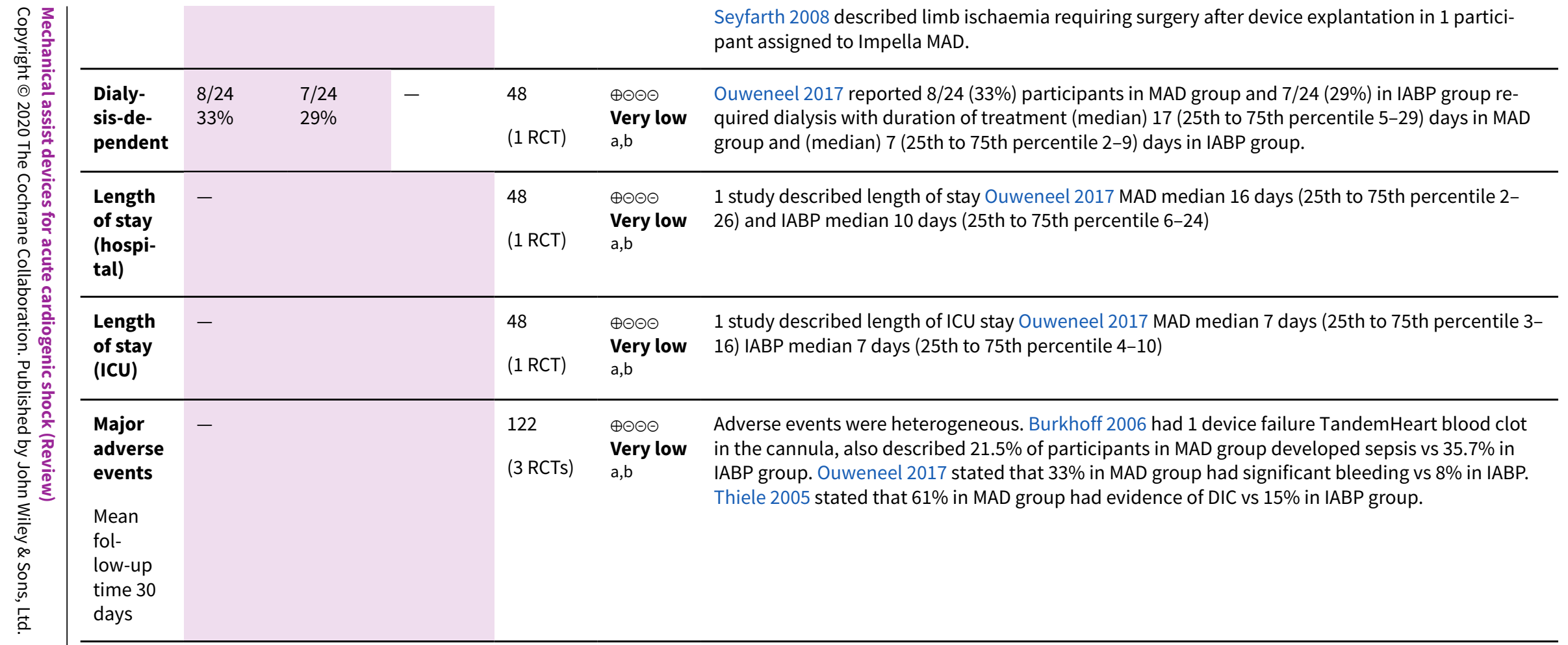

${ }^{\star}$ The risk in the intervention group (and its $95 \%$ confidence interval) is based on the assumed risk in the comparison group and the relative effect of the intervention (and its $95 \% \mathrm{Cl})$.

CI: confidence interval; CVA: cardiovascular accident; DIC: disseminated intravascular coagulation; IABP: intra-aortic balloon pump; ICU: intensive care unit; MACE: major adverse cardiovascular events; MAD: mechanical assist device; RCT: randomised controlled trial; RR: risk ratio.

\section{GRADE Working Group grades of evidence}

High certainty: we are very confident that the true effect lies close to that of the estimate of the effect.

Moderate certainty: we are moderately confident in the effect estimate: the true effect is likely to be close to the estimate of the effect, but there is a possibility that it is substantially different.

Low certainty: our confidence in the effect estimate is limited: the true effect may be substantially different from the estimate of the effect.

Very low certainty: we have very little confidence in the effect estimate: the true effect is likely to be substantially different from the estimate of effect.

$a^{a}$ Downgraded one level for study limitations: the majority of studies were at high or unclear risk of bias for at least one key domain.

b Downgraded two levels for imprecision: $95 \% \mathrm{Cl}$ is wide and includes the possibility of both harm and benefit, and the sample size is very low small. 


\section{B A C K G R O U N D}

\section{Description of the condition}

See Appendix 1 for a glossary of terms.

Acute cardiogenic shock (ACS) is a state of inadequate organ perfusion secondary to acute heart failure (Shekar 2016). This is characterised by persistent hypotension (systolic blood pressure less than $80 \mathrm{mmHg}$ to $90 \mathrm{mmHg}$ or mean arterial blood pressure $30 \mathrm{mmHg}$ lower than baseline, for more than 30 minutes) with reduction in Cardiac Index to less than $1.8 \mathrm{~L} /$ minute $/ \mathrm{m}^{2}$ without haemodynamic support or less than $2.0 \mathrm{~L} /$ minute $/ \mathrm{m}^{2}$ to 2.2 $\mathrm{L} /$ minute $/ \mathrm{m}^{2}$ with support and elevated filling pressures (left ventricular end-diastolic pressure (LVEDP) greater than $18 \mathrm{mmHg}$ or right ventricular end-diastolic pressure (RVEDP) greater than $10 \mathrm{mmHg}$ to $15 \mathrm{mmHg}$ ), a pulmonary capillary wedge pressure greater than $15 \mathrm{mmHg}$ in the setting of adequate or elevated filling pressure, and clinical features of hypoperfusion (cool extremities, decreased urine output, or altered sensorium) (Mandawat 2017; Reynolds 2008; Rihal 2015).

Despite advances in the management of cardiogenic shock, it remains the leading cause of death in hospitalised people, regardless of aetiologies (Chung 2012; WHO 2018). The incidence of ACS has increased two-fold from approximately 55,123 in 2004 to 126,555 in 2014 , according to the largest publicly available data in the USA (Mandawat 2017). Furthermore, the prognosis of ACS remains poor, with only $48 \%$ of people surviving from diagnosis to hospital discharge, despite higher rates of revascularisation and use of intra-aortic balloon pumps (IABP) (Mandawat 2017).

Myocardial infarction with left ventricular failure is the most common cause of cardiogenic shock, and cardiogenic shock occurs in approximately $5 \%$ to $8 \%$ of people hospitalised with ST elevation myocardial infarction (STEMI) and $2.5 \%$ of non-STEMI cases (Babaev 2005; Fox 2007; Hasdai 2000). When cardiogenic shock complicates an acute myocardial infarction, the reported mortality rate is between $85 \%$ and $90 \%$ (Goldberg 2001). Any cause of acute and severe left ventricular or right ventricular dysfunction can lead to cardiogenic shock. Acute myopericarditis, Takotsubo cardiomyopathy, and peripartum cardiomyopathy can all lead to reversible ventricular dysfunction which have good long-term prognosis, but only if the person can be supported through the acute phase of cardiac failure and cardiogenic shock (Emmert 2011; Howell 2016; Kato 1999; Omerovic 2016; Zalewska-Adamiec 2016).

\section{Description of the intervention}

For people with refractory cardiogenic shock despite maximal vasopressors, inotropic support and IABP, mortality approaches $100 \%$ with few people surviving (Hochman 2001). Survival in these cases may be possible by providing complete circulatory support with a mechanical assist device (MAD) (Hendry 1999; Hill 1986; Holman 1995).

MADs provide mechanical circulatory support (MCS) that has the ability to maintain vital organ perfusion, to unload the failing ventricle thus reducing intracardiac filling pressures which reduces pulmonary congestion, myocardial wall stress and myocardial oxygen consumption. MADs also have the ability to augment coronary perfusion by supporting the circulation during procedures which aim to treat the underlying cause of cardiogenic shock, such as revascularisation or ablation of ventricular arrhythmia (Friedel 1992; Rihal 2015). This can allow time for myocardial recovery (bridge to recovery) or allow time to come to a decision as to whether the person is a candidate for a longer-term ventricular assist device (VAD) either as a bridge to heart transplantation or as a destination therapy with a long-term VAD (Copeland 2004).

\section{How the intervention might work}

Current devices can be divided into categories: short-term versus long-term devices; paracorporeal versus intracorporeal; pulsatile versus continuous flow devices; full versus partial support devices; percutaneous versus surgical; and assist devices versus complete heart replacement (total artificial heart) (Sellke 2010).

In people presenting with critical circulatory instability, the chosen mechanical assistance should be rapidly available and easily implantable. Standard cardiopulmonary bypass is designed to ensure minutes to hours of support for people undergoing cardiac surgery. Extracorporeal membrane oxygenation (ECMO) provides continuous flow support to people with respiratory, cardiac or combined cardiopulmonary failure for days to weeks. Deoxygenated blood is drained from the venous system, the pulmonary system is bypassed by placing an oxygenator in parallel with the native lungs and pumped in a continuous manner using a centrifugal or roller pump back to the arterial circulation (Bartlett 2010). Cannulation can be obtained centrally (blood being drained directly from the right atrium and returned to the proximal ascending aorta) or peripherally (blood draining from the proximal femoral or jugular vein and returned to the carotid axillary or femoral artery), typically using the Seldinger technique, via an open or percutaneous approach (Chamogeorgakis 2013).

Venoarterial ECMO is available for cardiac or cardiopulmonary failure as a bridge to recovery, a bridge to definitive VAD or bridge to heart transplantation (Squiers 2016).

Similarly, short-term VADs can be rapidly implantable and provide extracorporeal or paracorporeal pulsatile or continuous flow. VADs support the function of the left ventricle (left ventricular assist device (LVAD)), right ventricle (right ventricular assist device (RVAD)) or both ventricles (biventricular assist device (BiVAD)) depending on what is required for that particular patient. They do not include an oxygenator, thus providing isolated cardiac support. These devices are more expensive but allow the people longer duration of circulatory support and greater opportunity to mobilise (Rihal 2015).

\section{Why it is important to do this review}

The leading cause of death internationally is cardiovascular disease, and cardiogenic shock is the penultimate point in which there is an opportunity to intervene (Lü 2016).

Cardiac surgeons are faced with increasingly complex cases with significant comorbidities, and with quality indexes, such as failure to rescue those who develop complications (e.g. postcardiotomy cardiogenic shock) being increasingly assessed. In order to operate on such complex cases, having the knowledge of the best current evidence will provide hospital trusts with the essential information in providing the necessary equipment and in training staff in the use of mechanical support devices. 
The National Institute for Health and Care Excellence (NICE) guidelines: Acute heart failure: diagnosis and management, state that "at an early stage, the specialist should have a discussion with a centre providing MCS about people with potentially reversible severe acute heart failure or people who are potential candidates for heart transplantation" (NICE 2014).

The 2016 European Society of Cardiology guidelines for the diagnosis and treatment of acute and chronic heart failure include MCS as a treatment option for people who cannot be stabilised on medical treatment alone. In addition to the uses described above, MCS, particularly ECMO, can be used as a 'bridge to decision' in people with cardiogenic shock to achieve haemodynamic stability, to allow consideration of long-term MCS and heart transplant to be evaluated (Ponikowski 2016).

The American Heart Association (AHA) and International Society for Heart and Lung Transplantations guidelines recommend patients with persistent cardiogenic shock with or without endorgan hypoperfusion, should be evaluated for MCS candidacy by a multidisciplinary team with expertise in the selection, implantation, and management of MADs (AHA 2012; ISHLT 2013). The most recent AHA scientific statement on the contemporary management of cardiogenic shock state, "We suggest that temporary MCS devices can be inserted in patients who are not expected to recover as early as possible in the course of CS [cardiogenic shock] as a bridge to recovery, bridge to a bridge, BTT, or bridge to decision strategy in appropriately selected patients with CS" (AHA 2017).

Many cardiology/cardiothoracic centres do not have timely access to temporary mechanical support devices. This review aims to assess the effectiveness of this treatment which would be valuable in guiding patient management and service planning.

\section{OB JECTIVES}

To assess whether mechanical assist devices improve survival in people with acute cardiogenic shock.

\section{METHODS}

\section{Criteria for considering studies for this review \\ Types of studies}

We included randomised controlled trials (RCTs) comparing MADs with best current intensive care management, including IABP and inotropic support. We included studies reported as full-text, those published as abstract only and unpublished data. We did not include cross-over trials as we were looking at survival data in the setting of people with an exceedingly high mortality risk.

\section{Types of participants}

We included all participants, irrespective of age (adults and children), with a diagnosis of ACS secondary to any cause. ACS was defined as "a state of organ hypoperfusion secondary to acute cardiac failure" (Shekar 2016). This is characterised by persistent hypotension (systolic blood pressure less than $80 \mathrm{mmHg}$ to 90 $\mathrm{mmHg}$ or mean arterial blood pressure $30 \mathrm{mmHg}$ lower than baseline, for more than 30 minutes) with reduction in Cardiac Index to less than $1.8 \mathrm{~L} /$ minute $/ \mathrm{m}^{2}$ without haemodynamic support or less than $2.2 \mathrm{~L} /$ minute $/ \mathrm{m}^{2}$ with support, and a pulmonary capillary wedge pressure greater than $15 \mathrm{mmHg}$ in the setting of adequate or elevated filling pressure (Reynolds 2008; Rihal 2015).

We included studies with a subset of eligible participants in the review. When more than one of the included trials was found to have less than $75 \%$ of people with the diagnosis of interest, we accepted that this reduces the validity of the results.

\section{Types of interventions}

The intervention group was any participant treated with a $M A D$, including ECMO, LVAD, RVAD or BiVAD, compared to the control group which was treated with best current intensive care management, including inotropic support and IABP.

\section{Types of outcome measures}

The reporting of outcomes was not a criteria for inclusion in the review.

\section{Primary outcomes}

1. Survival (measured to: discharge; 30 days; 1 year; end of followup).

2. Survival (measured to: transplant; unsupported cardiac function; end of follow-up).

\section{Secondary outcomes}

1. Quality of life (using a validated quality of life scale or questionnaire, measured to: discharge; 30 days; 6 months; 1 year; end of follow-up).

2. Major adverse cardiovascular events (measured to: discharge; 30 days; 6 months; 1 year; end of follow-up):

a. cerebrovascular accidents (persistent central neurological deficit for greater than 72 hours);

b. myocardial infarction;

c. acute limb ischaemia.

3. Dialysis-dependent (measured to: discharge; 30 days; 1 year; end of follow-up).

4. Length of hospital stay and length of intensive care unit stay.

5. Major adverse events, for example, deep sternal wound infection, prolonged ventilation greater than 72 hours (measured to: discharge; 30 days; 6 months; 1 year; end of follow-up).

\section{Search methods for identification of studies}

\section{Electronic searches}

We identified trials through systematic searches of the following bibliographic databases on 25 November 2019:

1. CENTRAL, Issue 11 (the Cochrane Library);

2. Epub Ahead of Print, In-Process \& Other Non-Indexed Citations, MEDLINE Daily and MEDLINE (Ovid, 1946 to 22 November 2019);

3. Embase (Ovid, 1980 to 2019 week 47);

4. Web of Science Core Collection (Clarivate Analytics, 1900 to 25 November 2019).

We adapted the preliminary search strategy for MEDLINE (Ovid) for use in the other databases (Appendix 2). We applied the Cochrane sensitivity-maximising RCT filter to MEDLINE (Ovid) and 
adaptations of it to the other databases, except CENTRAL (Lefebvre 2011).

We also conducted a search of ClinicalTrials.gov (www.ClinicalTrials.gov), the World Health Organization (WHO) International Clinical Trials Registry Platform (ICTRP) Search Portal (apps.who.int/trialsearch/), the UK Clinical Research Network Portfolio Database (public.ukcrn.org.uk), and Centerwatch (www.centerwatch.com) on 4 August 2019.

We searched all databases from their inception and we imposed no restriction on language of publication.

We searched relevant manufacturers' websites for trial information on 4 August 2019. Manufacturers of MADs that we have identified in previous searches were: Abbott (www.thoratec.com; www.sjmglobal.com), Getinge AB (www.maquet.com), Medtronic (www.medtronic.com), LivaNova (www.livanova.com), Hemovent (www.hemoventgmbh.com), ABIOMED (www.abiomed.com), www.reliantheart.com, Novacor (www.novacor.co.uk), MyLVAD (www.mylvad.com), Jarvik Heart (www.jarvikheart.com, www.terumoheart.net, www.sunshineheart.com).

\section{Searching other resources}

We checked reference lists of included studies and review articles for additional references. We contacted trial authors for missing data and through peer groups, identified any other ongoing trials. We examined any relevant retraction statements and errata for included studies.

\section{Data collection and analysis}

\section{Selection of studies}

Two teams of two review authors (JS, TN and CC, PA) independently screened titles and abstracts of all potential studies we identified as a result of the search for inclusion and code them as 'retrieve' (eligible or potentially eligible/unclear) or 'do not retrieve'. If there were any disagreements, a fifth review author arbitrated (KB). We retrieved the full-text study reports/ publications and two review authors (TN, JS) independently screened the full-text and identified studies for inclusion, and identified and recorded reasons for exclusion of the ineligible studies. We resolved any disagreements through discussion or, if required, we consulted a third review author (KB). We identified and excluded duplicates and collated multiple reports of the same study so that each study, rather than each report, was the unit of interest in the review. We recorded the selection process in sufficient detail to complete a PRISMA flow diagram (Liberati 2009).

\section{Data extraction and management}

We use Covidence (www.covidence.org), and extracted study characteristics and outcome data onto a form piloted on at least one study in the review. We included studies irrespective of whether measured outcome data were reported in a usable way.

Two review authors (CC and JS) extracted the following study characteristics.

1. Methods: study design, total duration of study, number of study centres and location, study setting, withdrawals, date of study.

2. Participants: number of participants randomised to the intervention, number of participants lost to follow-up, number of participants analysed, mean age, age range, gender, cause of cardiogenic shock, diagnostic criteria, baseline lung function, smoking history, lactate prior to initiating MCS.

3. Interventions: type of MADs, duration from diagnosis to intervention, duration of treatment, comparison, concomitant medications.

4. Outcomes: primary and secondary outcomes specified and collected, time points reported, number lost to follow-up, reasons for loss to follow-up.

5. Notes: funding for trial, notable conflicts of interest of trial authors.

Two review authors (CC and JS) independently extracted outcome data from included studies. We resolved disagreements by consensus or by involving a third review author (PA). One review author (TN) transferred data into Review Manager 5 (Review Manager 2014). We double-checked that data were entered correctly by comparing the data presented in the review with the study reports. A second review author (JS) spot-checked study characteristics for accuracy against the trial report.

\section{Assessment of risk of bias in included studies}

Two review authors (TNH and JS) independently assessed risk of bias for each study using the criteria outlined in the Cochrane Handbook for Systematic Reviews of Interventions (Higgins 2011). We resolved any disagreements by discussion or by involving another review author (PA). We assessed the risk of bias according to the following domains.

1. Random sequence generation.

2. Allocation concealment.

3. Blinding of participants and personnel.

4. Blinding of outcome assessment.

5. Incomplete outcome data.

6. Selective reporting.

7. Other bias.

We assessed selective outcome reporting bias by comparing the outcomes reported with the outcomes planned based on clinical trial registries/published protocols.

We graded each potential source of bias as high, low or unclear and provide a quote from the study report together with a justification for our judgement in the 'Risk of bias' table. We summarised the 'Risk of bias' judgements across different studies for each of the domains listed. Where information on risk of bias related to unpublished data or correspondence with a trialist, we noted this in the 'Risk of bias' table.

When considering treatment effects, we took into account the risk of bias for the studies that contributed to that outcome.

\section{Assessment of bias in conducting the review}

We conducted the review according to the published protocol and reported any deviations from it in the Differences between protocol and review section of the review (Ni hlci 2018).

\section{Measures of treatment effect}

It was our intention to conduct the meta-analysis using the most informative outcome and matching methods. Given that our 
primary outcome was patient survival this would (ideally) involve the use of individual participant data (IPD) and the tools of survival analysis. Therefore, we contacted the authors of studies identified in the review to request this data. If such data were available for a sufficient number of studies, we would have performed the metaanalysis using Cox Regression with mixed effects, following the recommendations of a review of methods (Austin 2017). We would then have conducted analysis using Poisson Regression modes and reported hazard ratios (HRs) (Simmonds 2005). However, we were unable to obtain IPD in all cases, and it was necessary to resort to using aggregated data. In the case that we were required to use aggregate data, we opted for binary survival at 30 days.

In addition to the primary measures, we collected and reported on outcomes such as overall survival, survival to transplant, survival to unsupported cardiac function and major adverse events where possible. We reported confidence intervals $(\mathrm{Cl})$ of time to death and time to major adverse events, along with point estimates. We planned to describe dichotomous data relating to status at a fixed time point using risk ratios (RRs) with corresponding $\mathrm{Cl}$ (Higgins 2011). For continuous outcomes, we calculated the mean difference (MD) between the treatment arms at the end of follow-up, if all trials measured the outcome on the same scale, otherwise we pooled standardised mean differences (SMDs), with $95 \% \mathrm{Cl}$.

\section{Unit of analysis issues}

Where studies reported multiple observations for the same participant, we included the data according to the closest time point where applicable (e.g. survival at 30 days and survival at one year). For quality of life data, we planned to include the last followup point collected and, for adverse event data, we included the first event in meta-analyses and described additional events for the same individual in the text.

In multiple-arm studies, where more than two interventional arms met the eligibility criteria, we planned to combine the two device arms to have a single comparator (best current intensive care management, including IABP and inotropic support).

As the intervention was in the setting of a life-threatening event, cross-over trials would not be possible, thus we did not anticipate finding cross-over trials.

To avoid unit of analysis errors in cluster-RCTs, we conducted the analysis at the same level as the allocation, using a summary measurement from each cluster. Then the sample size is the number of clusters and analysis proceeds as if the trial was individually randomised (though the clusters become the individuals). However, this might considerably, and unnecessarily, reduce the power of the study, depending on the number and size of the clusters; we planned to acknowledge this as a limitation.

\section{Dealing with missing data}

We contacted investigators or study sponsors to verify key study characteristics and obtain missing numerical outcome data where possible (e.g. when a study was identified as abstract only). Where this was not possible, and the missing data were thought to introduce serious bias, we explored the impact of including such studies in the overall assessment of results by a sensitivity analysis.

\section{Assessment of heterogeneity}

We assessed heterogeneity qualitatively by comparing the clinical and methodological characteristics of the included trials and by visual inspection of forest plots to assess the degree of overlap in the Cls.

We compared heterogeneity quantitatively using the $\mathrm{Chi}^{2}$ test of heterogeneity and the $I^{2}$ statistic in each analysis. We considered a $\mathrm{Chi}^{2}$ test resulting in $\mathrm{P}$ less than 0.1 indicating significant statistical heterogeneity. We interpreted $\mathrm{I}^{2}$ statistics in the following manner: $0 \%$ to $40 \%$, potentially not important; $30 \%$ to $60 \%$, moderate heterogeneity; $50 \%$ to $90 \%$, substantial heterogeneity and $75 \%$ to $100 \%$, considerable heterogeneity (Deeks 2011).

If we found very high heterogeneity, we first checked the data specifically, questioning any outliers. If the data were correct, we would have explored the results to understand why there was heterogeneity, and identify the factors that may be causing the variation between studies. If we found any modifiers, we would have cautiously reported the overall and subgroup analysis. We noted that the subgroup analysis was rarely randomised and we cautioned that our results should be considered observational and hypothesis-generating, rather than definitive.

If we had identified substantial or considerable heterogeneity, we would had report it and explored possible causes using prespecified subgroup analysis.

If the studies were too dissimilar in clinical (population, setting, intervention) and methodological heterogeneity (study design, risk of bias) and there was a high level of heterogeneity on visual inspection of the forest plots $\left(\mathrm{I}^{2}\right.$ greater than $90 \%$ and $\mathrm{Chi}^{2}$ with $\mathrm{P}$ less than 0.1 ), then we planned not to proceed with meta-analysis (Higgins 2011).

\section{Assessment of reporting biases}

If we were able to pool more than 10 trials, we planned to create and analyse a funnel plot to explore possible reporting biases for the primary outcomes.

\section{Data synthesis}

We undertook meta-analyses only where this was meaningful, that is, if the treatments, participants and the underlying clinical question were similar enough for pooling to make sense.

We would have used a random-effects model for pooling of treatment effects, since the studies would differ in the mixes of participants and in the implementations of MADs (Higgins 2011).

We would have presented all results with the corresponding 95\% Cls. We would have conducted all analyses according to the guidelines in the Cochrane Handbook for Systematic Reviews of Interventions (Higgins 2011), and with the statistical components of Review Manager 5 software (Review Manager 2014).

If sufficient, clinically similar studies had been available, we would have pooled the results in meta-analyses. For time-toevent data, we would have pooled HRs using the generic inverse variance facility of Review Manager 5 (Review Manager 2014). For dichotomous outcomes, we would have calculated the RR for each study and then pooled them. For continuous outcomes, we would have pooled the MDs between the treatment arms at the end of 
follow-up if all trials measure the outcome on the same scale, otherwise we would have pooled the SMDs.

We would have descriptively summarised the studies for which pooling of results was not possible.

\section{Subgroup analysis and investigation of heterogeneity}

We planned to carry out the following subgroup analyses.

1. Neonatal (less than 28 days of age)/paediatric ( 28 days to 16 years of age)/adult (greater than 16 years of age).

2. Cause of ACS/ischaemic heart disease/cardiomyopathy/acute myopericarditis.

3. MAD compared with IABP.

4. MAD compared with best medical therapy excluding IABP.

5. Percutaneous MADs (pMAD) (using Seldinger insertion technique) versus surgical MADs (inserted via sternotomy/ thoracotomy).

6. Long-term MCS devices (durable LVAD) compared with shortterm MCS devices (for example, ECMO, Impella).

7. Participants who had refractory cardiac arrest compared with participants with no cardiac arrest at the time of device implantation.

We used the following outcomes in subgroup analyses.

1. Survival (to discharge/30 days/1 year/to end of follow-up).

2. Major adverse events (to discharge/30 days/1 year/to end of follow-up).

We used the formal test for subgroup interactions in Review Manager 5 (Review Manager 2014).

\section{Sensitivity analysis}

We planned to carry out the following sensitivity analysis.

1. Only including studies with a low risk of bias across all domains.

\section{Brief economic commentary}

We developed a brief economic commentary based on current methods guidelines to summarise the availability and principal findings of trial-based and model-based economic evaluations (cost-analyses, cost-effectiveness analyses, cost-utility analyses and cost-benefit analyses) (Shemilt 2011; Shemilt 2017), that compare the use of MADs to best current intensive care management, including IABP and inotropic support. We identified relevant studies for this brief economic commentary during searches conducted for the review and during supplementary searches performed in accordance with search strategies developed by the Cochrane Economics Methods Group (Shemilt 2017). This commentary focused on the extent to which principal findings of eligible economic evaluations indicated that an intervention might be judged favourably (or unfavourably) from an economic perspective, when implemented in different settings.

\section{Reaching conclusions}

We based our conclusions only on findings from the quantitative or narrative synthesis of included studies for this review. We avoided making recommendations for practice and our implications for research would suggest priorities for future research and outline any remaining uncertainties in the area.

\section{Summary of findings and assessment of the certainty of the evidence}

We created a 'Summary of findings' table with the following outcomes and two time points.

\section{Primary}

1. Survival (30 days/end of follow-up).

2. Survival (to transplant or unsupported cardiac function/end of follow-up).

\section{Secondary}

1. Quality of life (using a validated quality of life scale or questionnaire; 30 days/end of follow-up).

2. Major adverse cardiovascular events ( 30 days/end of follow-up).

3. Dialysis-dependent (30 days/end of follow-up).

4. Length of hospital stay and length of intensive care unit stay.

5. Major adverse events, for example, deep sternal wound infection, prolonged ventilation (30 days/end of follow-up).

The comparison described in the 'Summary of findings' table would be MADs compared to best current intensive care management, including IABP and inotropic support.

We used the five GRADE considerations (study limitations, consistency of effect, imprecision, indirectness, and publication bias) to assess the quality of a body of evidence as it relates to the studies which contribute data to the meta-analyses for the prespecified outcomes. We used methods and recommendations described in Section 8.5 and Chapter 12 of the Cochrane Handbook for Systematic Reviews of Interventions (Higgins 2011), using GRADEpro GDT software (GRADEpro GDT). Two review authors (CC and JS) independently assessed the quality of the evidence and decided on downgrading and upgrading. If no agreement could be reached, a third review author (PA) resolved the disagreement. We justified all decisions to downgrade or upgrade the quality of the evidence using footnotes and we provided comments to aid the reader's understanding of the review where necessary. We planned to create one overall 'Summary of findings' table for our main analysis of MADs compared to best current intensive care management (inotropic support and IABP).

\section{RES U L T S}

\section{Description of studies}

See: Characteristics of included studies; Characteristics of excluded studies tables.

\section{Results of the search}

The searches resulted in 5616 citations and an additional 11 references were identified from the papers' reference lists and review of the ongoing clinical trials. We removed 1101 duplicates, resulting in 4515 citations for screening. See Figure 1 for full details of the process. 
Figure 1. Study flow diagram. RCT: randomised controlled trial.

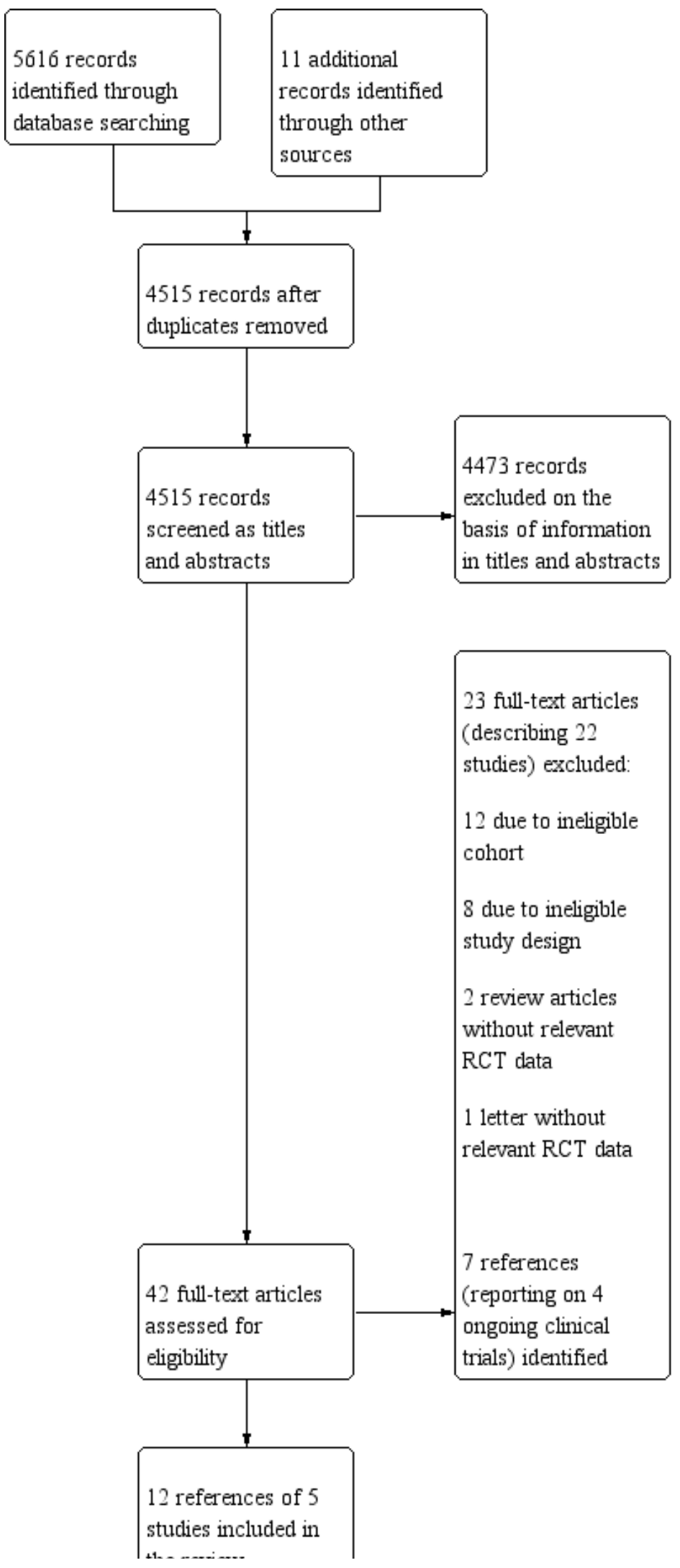


Figure 1. (Continued)

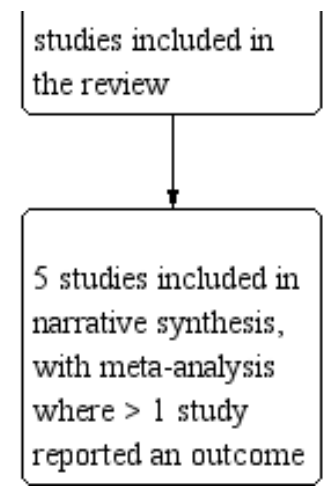

We excluded 4473 records on the basis of information in the title and abstract. We retrieved the full text of 42 references, which were screened independently by two review authors (TNH and CC). Thirty of these did not meet the inclusion criteria.

Twelve references of five RCTs met the inclusion criteria, and were included in the review. One trial had four publications (Thiele 2005), two trials had three publications (Ouweneel 2017; Seyfarth 2008), one trial had one paper (Burkhoff 2006), and one trial was described in a conference abstract only (Bonnefoy-Cudraz 2014).

The search for conference proceedings, meeting abstracts and ongoing trials in databases such as ClinicialTrials.gov (clinicaltrials.gov) yielded four ongoing trials relevant to this review (DanGer Shock Trial; ECLS-SHOCK; ECMO-CS; EuroShock).

\section{Included studies}

Five prospective RCTs randomised people with ACS to a MAD or best medical management including the use of an IABP. Two studies included all causes of ACS (Burkhoff 2006; Thiele 2005), and three studies included people with ACS only caused by acute myocardial infarction (Bonnefoy-Cudraz 2014; Ouweneel 2017; Seyfarth 2008). The two studies that included all causes of ACS randomised participants to the TandemHeart percutaneous VAD while those that included people with ACS due to acute myocardial infarction were randomised to the percutaneous Impella CP (Burkhoff 2006; Thiele 2005).

The total number of participants included in the five studies was 162 (13 to 41 participants included in each study). Four studies described the gender of the 148 participants, $75 \%$ of who were male (Burkhoff 2006; Ouweneel 2017; Seyfarth 2008; Thiele 2005). The number of centres ranged from one (Thiele 2005) to 12 (Burkhoff 2006). The mean age of participants receiving MAD ranged from 58 to 65.7 years and those in the control group from 58 to 67 years.
Three studies described the mean lactate concentration prior to initiating treatment (Burkhoff 2006; Ouweneel 2017; Thiele 2005); in the MAD group this ranged from $4.1 \mathrm{mg} / \mathrm{dL}$ (Burkhoff 2006) to $7.5 \mathrm{mg} / \mathrm{dL}$ (Ouweneel 2017), and in the IABP group from $3.8 \mathrm{mg} / \mathrm{dL}$ (Thiele 2005) to $8.9 \mathrm{mg} / \mathrm{dL}$ (Ouweneel 2017).

Of note, there were no studies investigating people after cardiotomy shock, and there were no studies that included people under the age of 18 years. In the people who presented with acute myocardial infarction, coronary revascularisation was performed prior to initiation of mechanical support in $69 \%$ of cases (Ouweneel 2017; Thiele 2005). Two studies described the time from diagnosis to initiation of support, which ranged from 4.5 hours to 11 hours and was similar in the MAD and IABP groups (Seyfarth 2008; Thiele 2005). Three studies described the duration of treatment (Burkhoff 2006; Seyfarth 2008; Thiele 2005); the mean ranged from 23 hours to four days, with those in Seyfarth 2008 having the shortest duration of support and Thiele 2005 the longest.

\section{Excluded studies}

We excluded 22 studies. Of these, 11 investigated an ineligible cohort whereby MADs were used in people with chronic heart failure, or in cohorts of high-risk percutaneous interventions (Characteristics of excluded studies table).

\section{Ongoing studies}

We found four ongoing studies (DanGer Shock Trial; ECLS-SHOCK; ECMO-CS; EuroShock; Characteristics of ongoing studies table).

\section{Risk of bias in included studies}

The risk of bias of each study is summarised in Figure 2 with details for each judgement provided in the Characteristics of included studies table. 
Figure 2. Risk of bias summary: review authors' judgements about each risk of bias item for each included study.

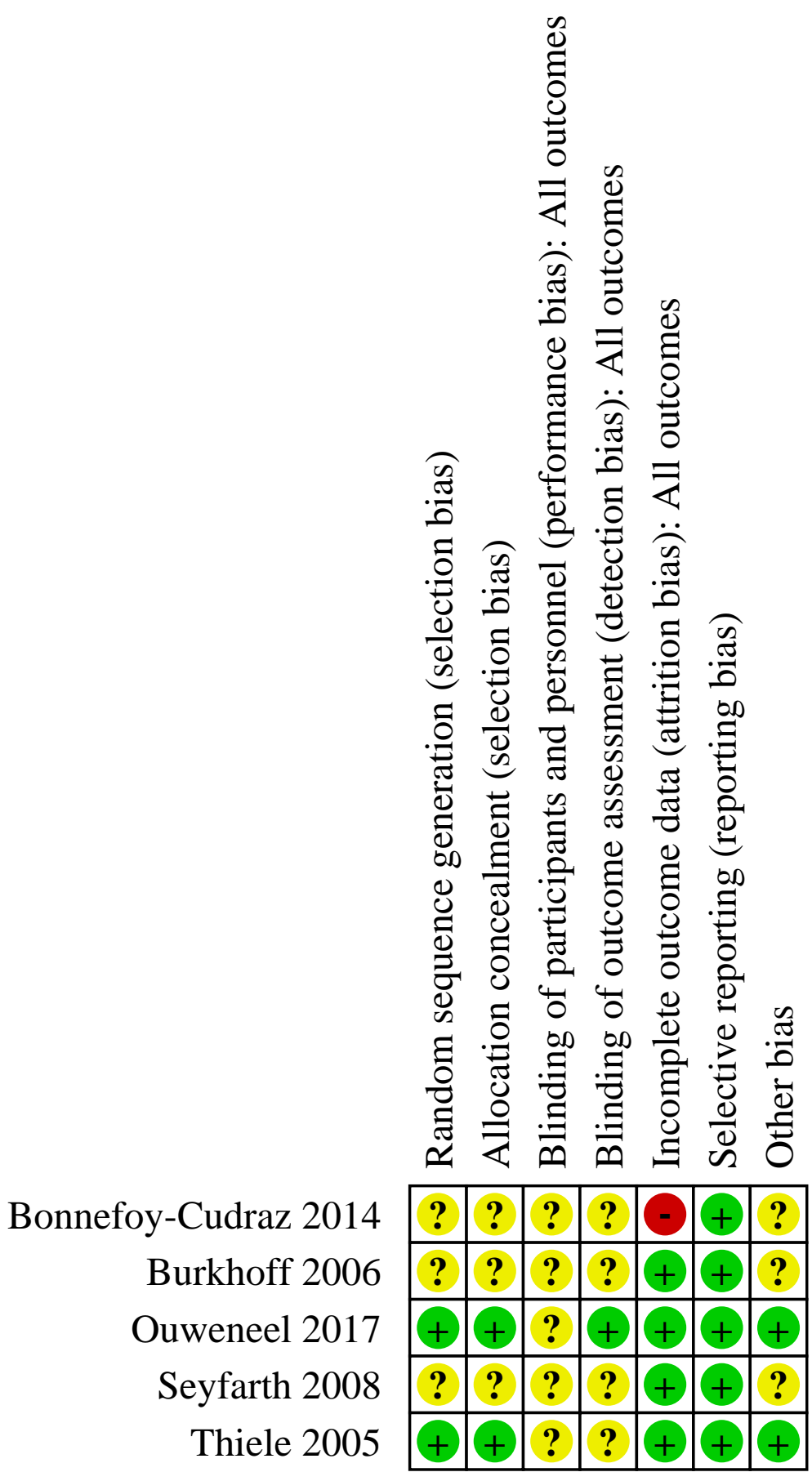




\section{Allocation}

\section{Random sequence generation}

Random sequence generation was unclear in three studies as there was no clear method described to how the randomisation processes was performed (Bonnefoy-Cudraz 2014; Burkhoff 2006; Seyfarth 2008). Two studies were clear regarding the timing of randomisation and method of doing so and were therefore at low risk of bias in this domain (Ouweneel 2017; Thiele 2005).

\section{Allocation concealment}

Allocation concealment was unclear in three studies (BonnefoyCudraz 2014; Burkhoff 2006; Seyfarth 2008). Seyfarth 2008 was a prospective two centre RCT that, after initial assessment of haemodynamics, randomly assigned eligible participants to either treatment with IABP or Impella LP2.5, but further details of the randomisation were not clarified. In Burkhoff 2006, there was a rollin phase of nine participants into the study prior to initiation of the randomisation of the subsequent 33 participants, the method of randomisation was not described. Bonnefoy-Cudraz 2014 did not describe any methods.

Allocation concealment was at low risk of bias in the remaining two studies (Ouweneel 2017; Thiele 2005). Thiele 2005 performed randomisation by drawing sealed envelopes and Ouweneel 2017 performed it in a 1:1 ratio using an Internet-based application.

\section{Blinding}

Performance bias unclear in all the studies. None of the studies described any methods of blinding of participants or personnel.

Detection bias was low in one study where the outcome assessment was clearly blinded as an independent clinical event committee adjudicated the events (Ouweneel 2017). Imaging parameters were assessed by independent local core laboratories that were blinded to the other trial data and randomisation outcome (Ouweneel 2017). The other four studies did not describe any attempts at blinding the outcome assessors, thus were deemed to have unclear risk for detection bias (Bonnefoy-Cudraz 2014; Burkhoff 2006; Seyfarth 2008; Thiele 2005).

\section{Incomplete outcome data}

Attrition bias was low in four studies as they described complete outcome data for the 30-day survival outcome. One participant was lost to follow-up when assessing the six-month outcome (Ouweneel 2017). One study was at high risk for attrition as two randomised participants were not included or accounted for in the analysis (Bonnefoy-Cudraz 2014).

\section{Selective reporting}

Selective reporting bias was low as all that was described in the methods of all five studies were reported and the data were complete in all studies.

\section{Other potential sources of bias}

There were no other identified biases in the included studies.

\section{Effects of interventions}

See: Summary of findings 1 Mechanical assist devices compared to intra-aortic balloon pump for acute cardiogenic shock at 30-day follow-up

Meta-analysis was performed only to assess the 30-day survival as there was insufficient data to perform any further meta-analysis.

\section{Survival (30 day)}

The results from the five studies with 162 participants showed that there was little or no effect in 30-day survival, with an RR of 1.01 (95\% $\mathrm{Cl} 0.76$ to 1.35$)$. The GRADE of the evidence was classed as very low which means we are uncertain about the finding.

One of the five trials was powered to assess an absolute reduction in the 30-day survival (Ouweneel 2017), the others had 30-day survival as secondary outcomes. Ouweneel 2017 reported that there was no significant difference in 30-day survival in the PMAD group (54\%) versus the IABP group (50\%), with an HR of 0.96 (95\% Cl 0.42 to 2.18).

Overall, of the 162 participants included, 84 had MAD, 40 of whom survived to 30 days (47.6\% survival) and 78 had IABP, of whom 39 survived ( $50 \%$ survival).

No study described whether participants went on to have a transplant or unsupported cardiac care.

Subgroup analysis assessing the type of MAD comparing those who received TandemHeart (two studies; Burkhoff 2006; Thiele 2005) to those who received other devices (Bonnefoy-Cudraz 2014: Impella LP 5.0 plus IABP; Ouweneel 2017: Impella CP plus IABP: Seyfarth 2008: Impella CP) demonstrated no statistical difference between the two groups' survival outcomes at 30 days $\left(\mathrm{Chi}^{2}=0.20, \mathrm{df}=1(\mathrm{P}\right.$ $=0.66) ; 1^{2}=0 \%$ ).

\section{Survival (to transplant or unsupported cardiac function/end of follow-up)}

None of the studies gave details regarding survival beyond 30 days and there were no data regarding the number of participants who survived to transplant or unsupported cardiac function.

\section{Quality of life}

None of the studies assessed quality of life in people who underwent treatment for ACS with IABP or MAD.

\section{Major adverse cardiovascular events}

Three studies described major adverse cardiovascular events in a heterogeneous manner (Ouweneel 2017; Seyfarth 2008; Thiele 2005). There were no clear definitions for major adverse cardiovascular events in any of the published studies. Cerebrovascular accident was described to have occurred in one participant who had a MAD and one participant who had IABP only; these were both in Ouweneel 2017 and both CVA were ischaemic. Ouweneel 2017 was the only study to describe if any cases had myocardial reinfarction reporting that this occurred in one participant who had MAD and two participants who had IABP only. Ouweneel 2017 described that one participant had a major vascular complication, with a retroperitoneal bleed after pMAD insertion. Limb ischaemia occurred in three of the MAD group and none in the IABP group. Thiele 2005 described that 
seven participants developed limb ischaemia following insertion of a 17-French arterial cannula. Limb ischaemia could be resolved by surgical approach in three participants and by percutaneous approach in four participants. Seyfarth 2008 described one case of limb ischaemia requiring surgery after device explantation in a participant assigned to Impella MAD.

\section{Dialysis-dependent}

Only one study described if any cases required renal replacement therapy following the episode of ACS (Ouweneel 2017). They described that $33 \%$ of the MAD group and $29 \%$ of the IABP group required renal replacement therapy.

\section{Length of hospital stay}

One study described the length of hospital stay after initiation of treatment (Ouweneel 2017). The mean length of stay in the MAD group was 16 days (range 3 days to 26 days) and in the IABP alone group 10 days (range 6 days to 24 days).

\section{Length of intensive care unit stay}

Ouweneel 2017 was the only study to report length of intensive care unit stay. The mean length of stay in the MAD group was 7 days (range 3 to 16 days), and in the IABP alone group was 7 days (range 4 to 10 days).

\section{Major adverse events}

Three studies described major adverse events (Burkhoff 2006; Ouweneel 2017; Thiele 2005). Burkhoff 2006 described one incident of TandemHeart failure and one event where the device had to be removed because of a device-related problem (blood clotting in the cannula; activated clotting time documented to be 182 seconds, which is less than the recommended 200 seconds to 250 seconds). They described that systemic infection or sepsis occurred in four $(21.1 \%)$ of the MAD group and five $(35.7 \%)$ of the IABP group. Ouweneel 2017 described major bleeding occurred in eight $(33 \%)$ of the MAD group and two $(8 \%)$ of the IABP group. They postulated the reason for this was those with mechanical support received heparin in addition to standard dual antiplatelet therapy after percutaneous coronary intervention (PCI). Thiele 2005 described that $13(61 \%)$ participants in the VAD group and three (15\%) participants in the IABP group had signs of disseminated intravascular coagulation (DIC). In the three participants with IABP, DIC was mild and could be resolved by substitution with antithrombin III. In eight participants with VAD, DIC was severe with subsequent haemorrhagic diathesis.

\section{DISCUSSION}

\section{Summary of main results}

This systematic review identified five prospective RCTs studying adults with ACS who were randomised to treatment with MADs or current best medical practice including the use of an IABP. Two studies included all causes of ACS and the MAD used was TandemHeart and two studies included only cases of cardiogenic shock secondary to acute myocardial infarction and the MAD used was Impella.

None of the studies were powered to assess if MADs improve survival in people with ACS, thus the primary objective of this review was unachievable. Four studies described 30 -day outcomes and there was little or no effect in the 30-day survival. No RCT assessed survival to transplant or unsupported cardiac function beyond six months.

Major adverse cardiovascular rates and major adverse event rates are not described consistently across the four trials and we are unable to conclude whether MAD led to an increased rate of complications. Three trials described limb ischaemia and found a trend towards an increase rate of limb ischaemia with MAD. This may be an issue with the catheter size as $33 \%$ of the participants in Thiele 2005 who had MAD with TandemHeart and a 17-French catheter had issues with peripheral limb ischaemia.

Based on the current published RCTs, we were unable to assess and formulate a brief economic commentary, and subgroup analysis was only possible for one outcome.

\section{Overall completeness and applicability of evidence}

There are several limitations to the evidence base reviewed. Both the number of trials that met the inclusion criteria for the review and also the number of participants included in the review were low. Not all the prespecified outcomes for the review were included in all the trials and some were not reported by any included trial. The condition studied, with its acute nature, rapid deterioration and high mortality make RCTs challenging to undertake.

There are several different devices for MCS, two different forms were included in this review; two trials (74 participants) utilised the TandemHeart and recruited between 2002 and 2004 and 2000 and 2003; two trials (74 participants) utilised the Impella device and recruited between 2012 and 2015 and 2004 and 2007. Further devices have been developed and are being developed and it is likely that there may be differences in the effects between devices. The small number of participants included did not permit subgroup analysis to compare effect sizes according to device type. With the available evidence, we were unable to determine if MCS did offload pharmacological support or not.

Research is often undertaken at larger academic medical institutions which often carry out higher volumes of procedures, it is established that health outcomes are improved in high-volume centres and it may be that outcomes would not be so good and adverse event rates higher in those undergoing MCS in smaller cardiac surgical centres.

\section{Quality of the evidence}

A summary of the findings and strength of evidence for comparing MCS and IABP can be found in Summary of findings 1.

The evidence for 30-day survival was downgraded to very-low certainty, due to study limitations (risk of bias in key domains) and very serious concerns about imprecision that related to the very small sample size and wide Cls including both the possibility of benefit and harm. Future evidence is highly likely to change the estimated effect.

The quality of evidence for the secondary outcomes was downgraded to very-low certainty. No studies described quality of life outcomes. Three studies described major adverse cardiovascular events 30-day follow-up (Ouweneel 2017; Seyfarth 2008; Thiele 2005), and three studies reported major adverse events at 30-day follow-up (Burkhoff 2006; Ouweneel 2017; Thiele 2005); 
reporting was heterogeneous without any clear definitions in any of the studies. Dialysis-dependence, length of hospital stay and length of intensive care unit stay were described in one trial each.

\section{Potential biases in the review process}

We all work to try to improve the outcomes in hopeless situations and we have an inherent bias to try to save lives. All trials under-represented women in their study populations ( $75 \%$ of the participants in the studies were male). Due to the nature of the intervention the trials were not blinded; however, due to the main outcome being survival it is unlikely that a lack of blinding had an impact on this. Despite extensive searches, it is possible that we were not able to identify all relevant studies.

\section{Agreements and disagreements with other studies or reviews}

The findings of this review are consistent with other reviews published in this field. The European Society of Cardiology updated their guidance on the management of cardiogenic shock complicating myocardial infarction (ESC 2019), they concluded that, despite an increasing number of PMAD data derived from clinical trials on the effectiveness safety, differential indications for different devices and optimal timing are limited. The authors of three of the RCTs described in this review, collaborated and published a review and collaborative meta-analysis including individual patient data concluded that there was no difference in mortality for 148 included participants. They found that there was improvement in arterial lactate and mean arterial blood pressure after device insertion. Counterbalancing this, however, were significantly more bleeding complications in the MAD group (Thiele 2017).

The Uspella registry reported on 15,259 people with acute myocardial infarction cardiogenic shock treated with Impella $(2.5$, CP or 5.0) in 1010 US hospitals and, of the total patients, $51 \%$ survived to explantation (Basir 2016 USpella registry). Of note, there were wide variations in survival observed on hospital sites, they found significant differences between survival at the time of explantation across various settings ( $30 \%$ survival rate among the lowest quintiles less than 1 Impella case/year versus $76 \%$ among the top quintile greater than 7 cases/year; $P<0.001)$. They identified two variables associated with improved survival, the timing of the MAD and haemodynamic monitoring. Clinicians used MAD as first-line treatment or as salvage after inotropic or balloon pump therapy failure. Data on MAD was available in 5571 people and they found that use of MCS devices as first-line treatment was associated with a $59 \%$ survival rate as compared with $52 \%$ when used as a salvage strategy $(P<0.001)$. When investigating the impact of invasive haemodynamic monitoring using pulmonary artery catheters on outcome in 13,984 people, they found that the survival rate among people who received haemodynamic monitoring was $63 \%$ compared with $49 \%$ in those who did not $(P<0.001)$. They found that older age was associated with a lower survival (OR 0.98 , $95 \% \mathrm{Cl} 0.97$ to $0.99 ; \mathrm{P}<0.0001)$. In people aged less than 50 years, $61.2 \%$ survived to explant versus $45.1 \%$ of people aged over 80 years of age) and that Impella used before $\mathrm{PCl}$ was independently associated with better survival (OR $1.34,95 \% \mathrm{Cl} 1.2$ to 1.5 ; $\mathrm{P}<$ $0.001)$, and that Impella CP was also associated with better survival compared with Impella2.5 (OR $1.28,95 \% \mathrm{Cl} 1.12$ to $1.47 ; \mathrm{P}=0.003)$.
International guidelines in ACS highlight the difficulty both ethically and practically in RCTs adequately powered to detect differences in clinical outcomes achieved as a result most of the trials have been underpowered and guideline recommendations are driven mostly by expert consensus (ESC 2019). Currently, early revascularisation is the only proven treatment to reduce mortality in acute myocardial infarction complicated by cardiogenic shock (Hochman 1999), but the extent of the revascularisation limited to the culprit lesion only (Thiele 2017 CULPRIT Shock Trial). But, despite the complexities and difficulties in performing clinical studies in cardiogenic shock, it now has been repeatedly shown that such trials can be successfully performed and international collaboration to build large cardiogenic shock research networks to answer the multiple open questions in the treatment of cardiogenic shock.

Currently there are four ongoing randomised control trials investigating the role of MAD in cardiogenic shock, powered to show a mortality benefit for MAD (one Impella, three VA ECMO). DanGer Shock 2019 has published the trial design along with the characteristics of the first 100 participants randomised. This collaborative trial will be the first adequately powered trial to address whether MCS with Impella CP can improve survival in acute myocardial cardiogenic shock. This trial has clear protocols published. Issues regarding consent are clear as in Denmark written informed proxy consent from relatives is obtained and in Germany the principle investigators' inability to obtain informed consent due to the urgency of the situation should be backed up by an independent physician, and the principle investigator assesses and acts according to supposed patients will. All centres must have direct access to an Internet-based randomisation system and if the patient is randomised to the treatment then Impella CP is placed before revascularisation. Patients with an out-of-hospital cardiac arrest with persistent Glasgow Coma Scale less than 8 after return of spontaneous circulation are excluded from this study and only patients with arterial lactate greater than $2.5 \mathrm{mmol} / \mathrm{L}$. In the ICU, patients irrespective of randomisation group are recommended to have invasive cardiovascular monitoring including a pulmonary artery catheter. No weaning attempts are done in the initial 48 hours, if there is stability at 48 hours, weaning should be attempted. If weaning leads to haemodynamic instability the device should be maintained and daily weaning attempts performed. After one week of support, escalation should be considered to venoarterial ECMO or LVAD. Guidance on the management of complications from the device is also clearly stipulated.

The published trials included in our review did not exclude people with out-of-hospital arrest. In the case of the largest trial, IMPRESS in Severe Shock trial, all their participants were mechanically ventilator prior to randomisation, and, overall, $92 \%$ of the included participants had an out-of-hospital cardiac arrest with a median duration of chest compression of more than 20 minutes and $25 \%$ of resuscitated participants were resuscitated for more than 45 minutes implying a significant risk of hypoxic cerebral injury (Ouweneel 2017). They found that the primary cause of death at six months was brain damage in $46 \%$ and death due to refractory cardiogenic shock occurred in $29 \%$ of the deceased participants. It has been speculated that the inclusion of out-of-hospital cardiac arrests contributed to the neutral result of the trial. Thus, the DanGer Shock trial has excluded these patients (DanGer Shock 2019). However, they include people who had a cardiac arrest in the catheterisation laboratory or after the arrival of emergency 
services. As we were unable to obtain individual patient data and the numbers were so small, we were unable to perform a sensitivity analysis for the cohort of patients without cardiac arrest in this systematic review and meta-analysis.

\section{AUTHORS' CONCLUSIONS \\ Implications for practice}

We are uncertain about the effects of mechanical circulatory support in improving survival for people with acute cardiogenic shock.

Further use of the technology, risk stratification and optimising the use protocols may help to improve the situation.

The results of this review should not have implication for practice.

\section{Implications for research}

The small number of participants included in this review and the very-low quality of evidence indicate that further research is highly likely to change the estimated effect.

An effort should be made for future trials to define and report complications in a consistent manner as this would allow comparisons across studies, and pooling of the data. This is crucial in this field as sample sizes in these studies tend to be quite small.

The devices available for mechanical circulatory support and clinicians experience in selecting patients and when to implant them is fast developing. Most participants included in this review were randomised pre-2010. Further research will be key in identifying whether there are subgroups of patients who can benefit from this treatment and the magnitude of this benefit.

\section{ACKNOWLEDGEMENTS}

We wish to acknowledge the help of the Cochrane Heart Group. We wish to acknowledge the input of Charlene Bridges, Information Specialist, for designing and running the search strategies and Andrea Takeda, Methods Specialist, who helped with analysing the data and formulating the 'Summary of findings' table. We wish to acknowledge the significant contribution made by Nicole Martin, the Managing Editor of Cochrane Heart, who guided and improved this review with constructive comments and invaluable advice. The additional comments and reviews from Mahmood Ahmad, Editor, and peer reviewers, Saraschandra Vallabhajosyula and Philippe Gaudard, who's comments greatly helped in improving this review. 


\section{R E F E R E N C E S}

\section{References to studies included in this review}

Bonnefoy-Cudraz 2014 \{published data only\}

Bonnefoy-Cudraz E, Huot L, Elbaz M, Cottin Y, Roux A, Bouchot $\mathrm{O}$, et al. Mechanical circulatory support with the Impella 5.0 and intra-aortic balloon pump for cardiogenic shock in acute myocardial infarction. The IMPELLA-STIC study. European Heart Journal 2014;1:1063.

\section{Burkhoff 2006 \{published data only\}}

Burkhoff D, Cohen H, Brunckhorst C, O'Neill WW, TandemHeart Investigators Group. A randomized multicenter clinical study to evaluate the safety and efficacy of the TandemHeart percutaneous ventricular assist device versus conventional therapy with intraaortic balloon pumping for treatment of cardiogenic shock. American Heart Journal 2006;152(3):469.e1-8.

\section{Ouweneel 2017 \{published data only\}}

NTR3450. IMPRESS in severe shock. www.who.int/trialsearch/ Trial2.aspx?TrialID=NTR3450 (first received 24 May 2012).

Ouweneel DM, Engstrom AE, Sjauw KD, Hirsch A, Hill JM, Gockel $\mathrm{B}$, et al. Experience from a randomized controlled trial with Impella 2.5 versus IABP in STEMI patients with cardiogenic pre-shock. Lessons learned from the IMPRESS in STEMI trial. International Journal of Cardiology 2016;202:894-6.

* Ouweneel DM, Eriksen E, Sjauw KD, van Dongen IM, Hirsch A, Packer EJ, et al. Percutaneous mechanical circulatory support versus intra-aortic balloon pump in cardiogenic shock after acute myocardial infarction. Journal of the American College of Cardiology 2017;69(3):278-87. [DOI: dx.doi.org/10.1016/ j.jacc.2016.10.022]

\section{Seyfarth 2008 \{published data only\}}

Seyfarth M, Bauer I, Sibbing D, Bott-Flugel L, Kastrati A, Schomig A. A prospective and randomized trial to compare a left ventricular assist device (Impella LP2.5) with IABP in patients with cardiogenic shock by acute myocardial infarction: the ISAR-SHOCK trial. Circulation 2007;116(16):929.

* Seyfarth M, Sibbing D, Bauer I, Frohlich G, Bott-Flugel L, Byrne R, et al. A randomized clinical trial to evaluate the safety and efficacy of a percutaneous left ventricular assist device versus intra-aortic balloon pumping for treatment of cardiogenic shock caused by myocardial infarction. Journal of the American College of Cardiology 2008;52(19):1584-8. [DOI: dx.doi.org/10.1016/j.jacc.2008.05.065]

Seyfarth M, Sibbing D, Gloeck T, Bott-Fluegel L, Bauer I, Kastrati A, et al. Two-year outcome with the LVAD Impella LP2.5 compared to IABP for patients with cardiogenic shock by myocardial infarction: long term follow-up of a randomized trial (ISAR-SHOCK). European Heart Journal 2009;1:157-8.

Thiele 2005 \{published data only\}

Thiele H, Boudriot E, Sick P, Niebauer J, Diederich KW, Hambrecht R, et al. Randomized comparison of intra-aortic balloon support versus a percutaneous left ventricular assist device in patients with acute myocardial infarction complicated by cardiogenic shock. Journal of the American College of Cardiology 2004;43(5):234A.

Thiele H, Boudriot E, Sick R, Diederich KW, Niebauer J, Hambrecht R, et al. Randomized comparison of intraaortic balloon support versus a percutaneous left ventricular assist device in patients with acute myocardial infarction complicated by cardiogenic shock. European Heart Journal 2004;25:73.

* Thiele H, Sick P, Boudriot E, Diederich KW, Hambrecht R, Niebauer J, et al. Randomized comparison of intra-aortic balloon support with a percutaneous left ventricular assist device in patients with revascularized acute myocardial infarction complicated by cardiogenic shock. European Heart Journal 2005;26(13):1276-83.

Thiele H, Sick P, Boudriot E, Diederich KW, Hambrecht R, Niebauer J, et al. Randomized comparison of intraaortic balloon support versus a percutaneous left-ventricular assist device in patients with revascularized acute myocardial infarction complicated by cardiogenic shock. European Heart Journal 2003;24:25

\section{References to studies excluded from this review}

Abraham 2012 \{published data only\}

Abraham WT, Anand I, Aranda JM Jr, Boehmer J, Costanzo MR, DeMarco T, et al. Randomized controlled trial of ventricular elastic support therapy in the treatment of symptomatic heart failure: rationale and design. American Heart Journal 2012;164(5):638-45.

\section{Abraham 2014 \{published data only\}}

Abraham W, Adamson P, Costa M, Nienaber C, Ince H, Erglis A, et al. Percutaneous ventricular restoration therapy using the parachute device in patients with ischemic dilated heart failure: pooled analysis of the first 100 patients treated for 1 year. European Journal of Heart Failure 2014;2:215.

\section{Agarwal 2015 \{published data only\}}

Agarwal S, Sud K, Martin J M, Menon V. Trends in the use of mechanical circulatory support devices in patients presenting with ST-segment elevation myocardial infarction. JACC. Cardiovascular Interventions 2015;8(13):1772-4.

Agrawal 2016 \{published data only\}

Agrawal H, Aggarwal K. Mechanical circulatory support in percutaneous coronary interventions: expanding the possibilities. Journal of Invasive Cardiology 2016;28(6):243-5.

Almond 2017 \{published data only\}

Almond C, Jaquiss J, Massicotte P, Ichord R, Kaltman J, Stylianou M, et al. The pumpkin trial study design and rationale. Cardiology in the Young 2017;27(4):S78-9.

Alushi 2019 \{published data only\}

Alushi B, Douedari A, Froehlig G, Knie W, Wurster TH, Leistner DM, et al. Impella versus IABP in acute myocardial 
infarction complicated by cardiogenic shock. Open Heart 2019;6(1):9.

\section{Anderson 2006 \{published data only\}}

Anderson M, Madani M, Raess D, Samuels L, Sun B, Sleeper L. Ventricular assist devices improve recovery outcomes in acute myocardial infarction cardiogenic shock: benchmark of US multicenter experience against SHOCK trial. American Journal of Cardiology 2006;98(8A):88M.

\section{Basir 2019 \{published data only\}}

Basir MB, Kapur NK, Patel K, Salam MA, Schreiber T, Kaki A, et al. Improved outcomes associated with the use of shock protocols: updates from the National Cardiogenic Shock Initiative. Catheterization and Cardiovascular Interventions 2019;93(7):1173-83.

\section{Birks 2009 \{published data only\}}

Birks EJ, Dulay M, O'Driscoll G, Jansz P, Wieselthaler G, Strueber M. Health-related QOL and neurocognitive status before and after implantation of the HeartWare left ventricular assist system. Journal of Cardiac Failure 2009;1:S46.

\section{Birks 2018 \{published data only\}}

Birks EJ, Drakos SG, Lowes BD, Patel SR, Selzman C, Slaughter MS, et al. Outcome and primary endpoint results from a prospective multicenter study of myocardial recovery using LVADs: remission from stage $d$ heart failure (RESTAGEHF). Journal of Heart and Lung Transplantation 2018;37 (4 Suppl 1):S142.

\section{Bluhm 2010 \{published data only\}}

Bluhm R. The epistemology and ethics of chronic disease research: further lessons from ECMO. Theoretical Medicine and Bioethics 2010;31(2):107-22.

\section{Bol 2019 \{published data only\}}

Bol ME, Suverein MM, Lorusso R, Delnoij TS, Brandon Bravo Bruinsma GJ, Otterspoor L, et al. Early initiation of extracorporeal life support in refractory out-of-hospital cardiac arrest: design and rationale of the INCEPTION trial. American Heart Journal 2019;210:58-68.

\section{Bronicki 2013 \{published data only\}}

Bronicki RA, Adachi I. The ventricular assist device: bridge to transplant. Bridge to recovery? Bridge to beyond? Pediatric Critical Care Medicine 2013;14(9):910-1.

\section{Brunner 2019 \{published data only\}}

Brunner S, Guenther SP, Lackermair K, Peterss S, Orban M, Boulesteix AL, et al. Extracorporeal life support in cardiogenic shock complicating acute myocardial infarction. Journal of the American College of Cardiology 2019;73(18):2355-7.

\section{Kar 2012 \{published data only\}}

Kar B, Basra SS, Shah NR, Loyalka P. Percutaneous circulatory support in cardiogenic shock interventional bridge to recovery. Circulation 2012;125(14):1809-17.

\section{Liu 2012 \{published data only\}}

Liu W, Barbagelata NA, Fujise K. Percutaneous hemodynamic support (Impella) in patients with advanced heart failure and/ or cardiogenic shock not eligible to protect ii trial. Journal of Cardiac Failure 2012;1:S101.

\section{Morici 2018 \{published data only\}}

Morici N, Oliva F, Ajello S, Stucchi M, Sacco A, Cipriani MG, et al. Management of cardiogenic shock in acute decompensated chronic heart failure: the ALTSHOCK phase II clinical trial. American Heart Journal 2018;204:196-201.

\section{NCT03101787 \{published data only\}}

NCT03101787. Early initiation of extracorporeal life support in refractory OHCA. clinicaltrials.gov/show/NCT03101787 (first received 5 April 2017).

\section{NCT03431467 \{published data only\}}

NCT03431467. Impella CP with VA ECMO for cardiogenic shock. clinicaltrials.gov/show/NCT03431467 (first received 13 February 2018).

\section{Patel 2011 \{published data only\}}

Patel MR, Thiele H, Smalling RW, Chandra P, Zhou Y, Cohen M, et al. A multicenter, randomized, controlled study of mechanical left ventricular unloading with counterpulsation to reduce infarct size prepercutaneous coronary intervention for acute myocardial infarction: rationale and design of the Counterpulsation Reduces Infarct Size Acute Myocardial Infarction trial. American Heart Journal 2011;162(1):47-55.

\section{Saeed 2013 \{published data only\}}

Saeed D, Arusoglu L, Gazzoli F, Hetzer R, Morshius M, Alloni A, et al. Results of the European clinical trial of Arrow CorAide left ventricular assist system. Artificial Organs 2013;37(2):121-7.

\section{Vallabhajosyula 2017 \{published data only\}}

Vallabhajosyula S, O'Horo JC, Antharam P, Ananthaneni S, Vallabhajosyula S, Stulak JM, et al. Concomitant intra-aortic balloon pump use in cardiogenic shock requiring venoarterial extracorporeal membrane oxygenation. Circulation. Cardiovascular Interventions 2018;11(9):e006930.

* Vallabhajosyula S, O'Horo JC, Antharam P, Ananthaneni S, Vallabhajosyula S, Stulak JM, et al. Venoarterial extracorporeal membrane oxygenation with concomitant Impella versus venoarterial extracorporeal membrane oxygenation for cardiogenic shock. ASAIO Journal 2017;17:17.

\section{References to ongoing studies}

\section{DanGer Shock Trial \{unpublished data only\}} NCT01633502. Danish cardiogenic shock trial (DanShock). clinicaltrials.gov/ct2/show/NCT01633502 (first received 4 July 2012).

\section{ECLS-SHOCK \{published data only\}}

NCT02544594. Clinical study of extra-corporal life support in cardiogenic shock complicating acute myocardial infarction. clinicaltrials.gov/show/NCT02544594 (first received 9 September 2015). 
NCT03637205. Extracorporeal life support in cardiogenic shock (ECLS-SHOCK). clinicaltrials.gov/ct2/show/NCT03637205 (first received 17 August 2018).

\section{ECMO-CS $\{$ published data only\}}

NCT02301819. Extracorporeal membrane oxygenation in the therapy of cardiogenic shock (ECMO-CS). clinicaltrials.gov/ct2/ show/NCT02301819 (first received 26 November 2014).

\section{EuroShock \{published data only\}}

NCT03813134. Testing the value of novel strategy and its cost efficacy in order to improve the poor outcomes in cardiogenic shock. clinicaltrials.gov/show/NCT03813134 (first received 23 January 2019).

\section{Additional references}

\section{AHA 2012}

Peura JL, Colvin-Adams M, Francis GS, Grady KL, Hoffman TM, Jessup M, et al, on behalf of the American Heart Association Heart Failure and Transplantation Committee of the Council on Clinical Cardiology, Council on Cardiopulmonary, Critical Care, Perioperative and Resuscitation, Council on Cardiovascular Disease in the Young, Council on Cardiovascular Nursing, Council on Cardiovascular Radiology and Intervention, and Council on Cardiovascular Surgery and Anesthesia. Recommendations for the use of mechanical circulatory support: device strategies and patient selection: a scientific statement from the American Heart Association. Circulation 2012;126:2648-67.

\section{AHA 2017}

van Diepen S, Katz JN, Albert NM, Henry TD, Jacobs AK, Kapur NK, et al. Contemporary management of cardiogenic shock: a scientific statement from the American Heart Association. Circulation 2017;136(16):e232-68.

\section{Austin 2017}

Austin PC. A tutorial on multilevel survival analysis: methods, models and applications. International Statistical Review 2017;85(2):185-203.

\section{Babaev 2005}

Babaev A, Frederick PD, Pasta DJ, Every N, Sichrovsky T, Hochman JS. Trends in management and outcomes of patients with acute myocardial infarction complicated by cardiogenic shock. JAMA 2005;294:448-54.

\section{Bartlett 2010}

Bartlett RH, Gattinoni L. Current status of extracorporeal life support (ECMO) for cardiopulmonary failure. Minerva Anestesiologica 2010;76:534-40.

\section{Basir 2016 USpella registry}

Basir MB, Schrieber TL, Grines CL, Dixon SR, Moses JW, Mani BS, et al. Effect of early initiation of mechanical circulatory support on survival in cardiogenic shock. American Journal of Cardiology 2017;119:845-51.

\section{Chamogeorgakis 2013}

Chamogeorgakis T, Lima B, Shaffii AE, Nagpal D, Pokersnik JA, Navia JL, et al. Outcomes of axillary artery side graft cannulation for extracorporeal membrane oxygenation. Journal of Thoracic and Cardiovascular Surgery 2013;145:1088-92.

\section{Chung 2012}

Chung SY, Sheu JJ, Lin YJ, Sun CK, Chang LT, Chen YL, et al. Outcomes of patients with profound cardiogenic shock after cardiopulmonary resuscitation and prompt extracorporeal membrane oxygenation support. A single-centre observational study. Circulation 2012;6:1385-92.

\section{Copeland 2004}

Copeland JG, Smith RG, Arabia FA, Nolan PE, Sethi GK, Tsau PH, et al. Cardiac replacement with a total artificial heart as a bridge to transplantation. New England Journal of Medicine 2004;351(9):859-67.

\section{DanGer Shock 2019}

Udesen NJ, Moller JE, Lindholm MG, Eiskjaer H, Schafer A, Werner N, et al. Rationale and design of DanGer shock: DanishGerman cardiogenic shock trial. American Heart Journal 2019;214:69-8.

\section{Deeks 2011}

Deeks JJ, Higgins JP, Altman DG. Chapter 9: Analysing data and undertaking meta-analyses. In: Higgins JP, Green S editor(s). Cochrane Handbook for Systematic Reviews of Interventions Version 5.1.0 (updated March 2011). The Cochrane Collaboration, 2011. Available from handbook.cochrane.org.

\section{Emmert 2011}

Emmert MY, Prêtre R, Ruschitzka F, Krhenmann F, Falk V, Wilhelm MJ. Peripartum cardiomyopathy with cardiogenic shock: recovery after prolactin inhibition and mechanical support. Annals of Thoracic Surgery 2011;91(1):274-6.

\section{ESC 2019}

Thiele H, Ohman EM, deWaha-Thiele S, Zeymer U, Desch S. Management of cardiogenic shock complicating myocardial infarction: an update 2019. European Heart Journal 2019;40:2671-83.

\section{Fox 2007}

Fox KA, Anderson FA Jr, Dabbous OH, Steg PG, Lopez-Sendon J, Vande Werf $F$, et al. Intervention in acute coronary syndromes: do patients undergo intervention on the basis of their risk characteristics? The Global Registry of Acute Coronary Events (GRACE). Heart 2007;93:177-82.

\section{Friedel 1992}

Friedel N, Viazis P, Schiessler A, Warnecke H, Hennig E, Trittin A, et al. Recovery of end-organ failure during mechanical circulatory support. European Journal of Cardiothoracic Surgery 1992;6(10):519-22

\section{Goldberg 2001}

Goldberg RJ, Gore JR, Thompson CA, Gurwitz JH. Recent magnitude of and temporal trends (1994-1997) in the incidence and hospital death rates of cardiogenic shock complicating 
acute myocardial infarction: the second National Registry of Myocardial Infarction. American Heart Journal 2001;141:65-72.

\section{GRADEpro GDT [Computer program]}

McMaster University (developed by Evidence Prime) GRADEpro GDT. Hamilton (ON): McMaster University (developed by Evidence Prime), 2015.Available at gradepro.org.

\section{Hasdai 2000}

Hasdai D, Harrington RA, Hochman JS, Califf RM, Battler A, Box JW, et al. Platelet glycoprotein IIb/IIla blockade and outcome of cardiogenic shock complicating acute coronary syndromes without persistent ST-segment elevation. Journal of American College of Cardiology 2000;36:685-92.

\section{Hendry 1999}

Hendry PJ, Masters RG, Mussivand TV, Smith S, Davies RA, Finlay S, et al. Circulatory support for cardiogenic shock due to acute myocardial infarction: a Canadian experience. Canadian Journal of Cardiology 1999;15(10):1090-4.

\section{Higgins 2011}

Higgins JP, Green S, editor(s). Cochrane Handbook for Systematic Reviews of Interventions Version 5.1.0 (updated March 2011). The Cochrane Collaboration, 2011. Available from handbook.cochrane.org.

\section{Hill 1986}

Hill JD, Farrar DJ, Hershon JJ, Compton PG, Avery GJ 2nd, Levin BS, et al. Use of a prosthetic ventricle as a bridge to cardiac transplantation for postinfarction cardiogenic shock. New England Journal of Medicine 1986;314:626-8.

\section{Hochman 1999}

Hochman JS, Sleeper LA, Webb JG, Sanborn TA, White HD, Talley JD, et al. Early revascularization in acute myocardial infarction complicated by cardiogenic shock. SHOCK Investigators. Should we emergently revascularize occluded coronaries for cardiogenic shock. New England Journal of Medicine 1999;341:625-34.

\section{Hochman 2001}

Hochman JS, Sleeper LA, White HD, Dzavik V, Wong SC, Menon V, et al. One year survival following early revascularization for cardiogenic shock. JAMA 2001;285:190-2.

\section{Holman 1995}

Holman WL, Roye GD, Bourge RC, McGiffin DC, lyer SS, Kirklin JK. Circulatory support for myocardial infarction with ventricular arrhythmias. Annals of Thoracic Surgery 1995;59(5):1230-1.

\section{Howell 2016}

Howell E, Paivanas N, Stern J, Vidula H. Treatment of acute necrotizing eosinophilic myocarditis with immunosuppression and mechanical circulatory support. Circulation. Heart Failure 2016;9(12):e003665.

\section{ISHLT 2013}

Feldman D, Pamboukian SV, Teuteberg JJ, Birks E, Lietz K, Moore SA, et al. The 2013 International Society for Heart and
Lung Transplantation guidelines for mechanical circulatory support: executive summary. Journal of Heart and Lung Transplantation 2013;32:157-87.

\section{Kato 1999}

Kato S, Morimoto S, Hiramitsu S, Nomura M, Ito T, Hishida H. Use of percutaneous cardiopulmonary support of patients with fulminant myocarditis and cardiogenic shock for improving prognosis. American Journal of Cardiology 1999;83(4):623-5.

\section{Lefebvre 2011}

Lefebvre C, Manheimer E, Glanville J. Chapter 6: Searching for studies. In: Higgins JP, Green S, editor(s). Cochrane Handbook for Systematic Reviews of Interventions Version 5.1.0 (updated March 2011). The Cochrane Collaboration, 2011. Available from handbook.cochrane.org.

\section{Liberati 2009}

Liberati A, Altman DG, Tetzlaff J, Mulrow C, Gotzsche PC, loannidis JP, et al. The PRISMA statement for reporting systematic reviews and meta-analyses of studies that evaluate health care interventions: explanation and elaboration. PLOS Medicine 2009;6(7):e1000100.

\section{Lü 2016}

Lü TF. Prevention: some important steps forward, but many unmet needs in a world with cardiovascular disease as the leading cause of death. European Heart Journal 2016;37(42):3179-81.

\section{Mandawat 2017}

Mandawat A, Rao SV. Percutaneous mechanical circulatory support devices in cardiogenic shock. Circulation. Cardiovascular Interventions 2017;10:e004337.

\section{NICE 2014}

National Institute for Health and Care Excellence. Acute heart failure: diagnosis and management. nice.org.uk/guidance/ cg187 (accessed prior to 7 May 2020).

\section{Omerovic 2016}

Omerovic E. Takotsubo syndrome - scientific basis for current treatment strategies. Heart Failure Clinics 2016;12(4):577-86.

\section{Ponikowski 2016}

Ponikowski P, Voors AA, Anker SD, Bueno H, Cleland JG, Coats AJ, et al. ESC Guidelines for the diagnosis and treatment of acute and chronic heart failure. European Heart Journal 2016;37(27):2129-200

\section{Review Manager 2014 [Computer program]}

Nordic Cochrane Centre, The Cochrane Collaboration Review Manager 5 (RevMan 5). Version 5.3. Copenhagen: Nordic Cochrane Centre, The Cochrane Collaboration, 2014.

\section{Reynolds 2008}

Reynolds H, Hochman S. Cardiogenic shock: current concepts and improving outcomes. Circulation 2008;117:686-97. 


\section{Rihal 2015}

Rihal CS, Naidu SS, Givertz MM, Szeto WY, Burke JA, Kapur NK, et al. $2015 \mathrm{SCAl} / \mathrm{ACC} / \mathrm{HFSA} / \mathrm{STS}$ clinical expert consensus statement on the use of percutaneous mechanical circulatory support devices in cardiovascular care. Journal of the American College of Cardiology 2015;65(19):e7-e26.

\section{Sellke 2010}

Sellke FW, del Nido PH, Swanson SJ. Sabiston \& Spencer Surgery of the Chest. 8th edition. Vol. II. Philadelphia (PA): Saunders Elsevier, 2010.

\section{Shekar 2016}

Shekar K, Gregory SD, Fraser JF. Mechanical circulatory support in the new era: an overview. Critical Care (London, England) 2016;20(1):66.

\section{Shemilt 2011}

Shemilt I, Mugford M, Byford S, Drummond M, Eisenstein E, Knapp M, et al. Chapter 15: Incorporating economics evidence In: Higgins JP, Green S, editor(s). Cochrane Handbook for Systematic Reviews of Interventions Version 5.1.0 (updated March 2011). The Cochrane Collaboration, 2011. Available from handbook.cochrane.org.

\section{Shemilt 2017}

Shemilt I, Mugford M, Vale L, Craig D, Campbell and Cochrane Economics Methods Group. Searching NHS EED and HEED to inform development of economic commentary for Cochrane intervention reviews. www.methods.cochrane.org/economics/ workshops (accessed 13 July 2017).

\section{Simmonds 2005}

Simmonds MC, Higgins JP, Stewart LA, Tierney JF, Clarke MI, Thompson SG. Meta-analysis of individual patient data from randomized trials: a review of methods used in practice. Clinical Trials 2005;2:209-17.

\section{Squiers 2016}

Squiers JJ, Lima B, DiMaio JM. Contemporary extracorporeal membrane oxygenation therapy in adults: fundamental

\section{CHARACTERISTICS OF STUDIES}

Characteristics of included studies [ordered by study ID] principles and systematic review of the evidence. Journal of Thoracic and Cardiovascular Surgery 2016;152(1):20-32.

\section{Thiele 2017}

Thiele H, Jobs A, Ouweneel DM, Henriques JP, Seyfarth M, Desch $S$, et al. Percutaneous short term active mechanical support devices in cardiogenic shock: a systematic review and collaborative meta-analysis of randomized trials. European Heart Journal 2017;38:3523-31.

\section{Thiele 2017 CULPRIT Shock Trial}

Thiele H, Kin I, Sandri M, Fuernau G, de Waha S, Meyer-Saraei R, et al. $\mathrm{PCl}$ strategies in patients with acute myocardial infarction and cardiogenic shock. New England Journal of Medicine 2017;377:2419-32.

\section{WHO 2018}

World Health Organization. Global health estimates 2016: deaths by cause, age, sex, by country and by region, 2000-2016. www.who.int/healthinfo/global_burden_disease/estimates/en/ index1.html (accessed prior to 7 May 2020).

\section{Zalewska-Adamiec 2016}

Zalewska-Adamiec M, Bachorzewska-Gajewska H, TomaszukKazberuk A, Nowak K, Drozdowski P, Bychowski J, et al. Takotsubo cardiomyopathy: serious early complications and two-year mortality - a 101 case study. Netherlands Heart Journal 2016;24(9):511-9.

\section{References to other published versions of this review Ni hlci 2018}

Ni hlci T, Boardman HM, Baig K, Aifesehi PE, Stafford JL, Cernei $\mathrm{C}$, et al. Mechanical assist devices for acute cardiogenic shock. Cochrane Database of Systematic Reviews 2018, Issue 4. [DOI: 10.1002/14651858.CD013002]

* Indicates the major publication for the study

Bonnefoy-Cudraz 2014

\title{
Study characteristics
}

Methods

\author{
Study design: RCT \\ Study grouping: not described \\ Total duration of the study: not described \\ Number of study sites and locations: not described \\ Study setting: not described \\ Date of the study: not described
}


Bonnefoy-Cudraz 2014 (Continued)
Participants
People with CS secondary to AMI
Baseline characteristics not described
Total number of participants randomised to intervention: 15
Number of participants lost to follow-up: 2
Number of participants analysed: 13

Interventions Impella LP5.0 + IABP vs IABP alone

\section{Intervention characteristics}

MCS

- Type of MCS: LVAD Impella LP5.0 + IABP

- Duration from diagnosis to intervention: N/A

- Duration of treatment: N/A

- Concomitant medications: N/A

IABP

- Duration from diagnosis to intervention: N/A

- Duration of treatment: N/A

- Concomitant medications: N/A

Outcomes Haemodynamic effect

- $\mathrm{CPI}$ after 12 hours of support was increased but not significantly in people with the Impella LP5.0 + IABP compared with people with IABP (LP5.0 + IABP: CPI 0.08 (SD 0.08) watt/m²; IABP: CPI -0.02 (SD $0.25)$ watt $\left./ \mathrm{m}^{2} ; P=0.415\right)$.

Survival: 30 day

- 30-day mortality was $28.6 \%$ (2 deaths 1 week after inclusion) in Impella LP5.0 + IABP group compared to 0 in IABP group.

Survival measured to: transplant: unsupported cardiac function

- Not reported

Quality of life

- Not reported

Major adverse cardiovascular events

- Not reported

Dialysis-dependent

- Not reported

Length of hospital stay

- Not reported

Length of ICU stay

- Not reported

Major adverse events 
Bonnefoy-Cudraz 2014 (Continued)

- Not reported

\begin{tabular}{|c|c|c|}
\hline Identification & $\begin{array}{l}\text { Sponsorship source: } \\
\text { Country: France } \\
\text { Setting: not reported } \\
\text { Authors name: E Bonı } \\
\text { Institution: Hospital L } \\
\text { Email: N/A } \\
\text { Address: N/A } \\
\text { Year: } 2014\end{array}$ & $\begin{array}{l}\text { th stated } \\
\text { uis Pradel of Bron, Intensive Cardiac Care, Lyon, France } \\
\text { uis }\end{array}$ \\
\hline Notes & \multicolumn{2}{|c|}{ Published as a conference abstract. } \\
\hline \multicolumn{3}{|l|}{ Risk of bias } \\
\hline Bias & Authors' judgement & Support for judgement \\
\hline $\begin{array}{l}\text { Random sequence genera- } \\
\text { tion (selection bias) }\end{array}$ & Unclear risk & Method of selection not described. \\
\hline $\begin{array}{l}\text { Allocation concealment } \\
\text { (selection bias) }\end{array}$ & Unclear risk & Method of allocation concealment not described. \\
\hline $\begin{array}{l}\text { Blinding of participants } \\
\text { and personnel (perfor- } \\
\text { mance bias) } \\
\text { All outcomes }\end{array}$ & Unclear risk & Not described. \\
\hline
\end{tabular}

\begin{tabular}{|c|c|c|}
\hline $\begin{array}{l}\text { Blinding of outcome as- } \\
\text { sessment (detection bias) } \\
\text { All outcomes }\end{array}$ & Unclear risk & Not described. \\
\hline $\begin{array}{l}\text { Incomplete outcome data } \\
\text { (attrition bias) } \\
\text { All outcomes }\end{array}$ & High risk & 2 participants randomised not included or accounted for in analysis. \\
\hline $\begin{array}{l}\text { Selective reporting (re- } \\
\text { porting bias) }\end{array}$ & Low risk & $\begin{array}{l}\text { Outcomes were objective and described for all cases that were accounted for } \\
\text { in analysis. }\end{array}$ \\
\hline Other bias & Unclear risk & $\begin{array}{l}\text { No information regarding how they dealt with minimising bias. The full paper } \\
\text { has not been published. }\end{array}$ \\
\hline
\end{tabular}

Burkhoff 2006

\section{Study characteristics}

\begin{tabular}{ll}
\hline Study design: $\mathrm{RCT}$ \\
Study grouping: parallel group \\
Total duration of the study: 2 years
\end{tabular}


Burkhoff 2006 (Continued)

Number of study sites and locations: 12 sites in USA and Switzerland

Study setting: tertiary referral sites

Date of the study: April 2002 to April 2004

Participants

\section{Baseline characteristics}

MCS

- Age (mean): 65.7 (SD 13.8) years

- Male gender n(\%): 14 (74\%)

- Lactate (mean): 4.1 (SD 4) mmol/L

- Smokers n (\%): N/A

- $p H: \mathrm{N} / \mathrm{A}$

- Lung function: N/A

- Cause of CS: $57 \%$ AMI, most of the remaining had decompensated chronic heart failure.

IABP

- Age (mean): 60.3 (SD 10.7) years

- Male gender $n(\%): 9$ (64\%)

- Lactate (mean): 5.5 (SD 4.7) mmol/L

- Smokers n (\%): N/A

- $p H: \mathrm{N} / \mathrm{A}$

- Lung function: N/A

- Cause of CS: $71 \%$ AMI, most of the remaining had decompensated chronic heart failure.

Inclusion criteria: aged $\geq 18$ years; presented within 24 hours of developing CS; ad indwelling right catheter for measurement of PCWP and Cardiac Index; CS defined as Cardiac Index V2.2 L/ $/ \mathrm{m}^{2} /$ minute, MAP $70 \mathrm{mmHg}$, PCWP $15 \mathrm{mmHg}$ and evidence of end-organ hypoperfusion (e.g. decreased urine output, altered mental status) or the need for administration of high-dose pressor or inotropic support (or both) to maintain the participant out of CS. People already having an IABP were eligible if they still met haemodynamic criteria for CS.

Exclusion criteria: isolated right-side heart failure, coagulopathy, sepsis, severe peripheral vascular disease, stroke within 6 months, $\geq 2+$ aortic regurgitation and ventricular septal rupture.

Total number of participants randomised to intervention: 33

Number of participants lost to follow-up: 0

Number of participants analysed: 33

Interventions

MCS vs IABP

\section{Intervention characteristics}

MCS

- Type of MCS: TandemHeart percutaneous VAD. 21-French left atrial drainage cannula, extracorporeal centrifugal pump rotating at $7500 \mathrm{rpm}$, femoral arterial cannula 15-French to 17-French that extended to the iliac artery and a microprocessor based pump controller.

- Duration from diagnosis to intervention: N/A

- Duration of treatment: 2.5 days

- Concomitant medications: pressors and inotropic support in all cases

IABP

- Duration from diagnosis to intervention: N/A

- Duration of treatment: 2.5 days 
- Compared with IABP participants receiving support with MCS had significantly greater increases in Cardiac Index and greater decreases in PCWP. Changes in the cardiac output were directly proportional to changes in Cardiac Index and increased by 2.1 (SD 1.3) L/minute $(P<0.05)$. MAP did not change in IABP group, whereas it increased significantly in MCS group.

\section{Overall outcomes}

- Proportion of participants dying while on support (or within 24 hours of device removal), being bridged to another treatment or capable of being weaned was similar in both groups. Overall, 30-day survival was similar in both groups (MCS: 53\%; IABP: 64\%).

Survival

- 30-day survival: MCS: 10/19 (53\%); IABP: 9/14 (64\%)

- 1-year survival: not described

Survival measured to: transplant: unsupported cardiac function

- Not described

Quality of life

- Not measured

Major adverse cardiovascular events

- MCS: system failure 1, right side of the heart failure 1 , cardiac tamponade 2 , damage to blood vessels 2, distal leg ischaemia 4

- IABP: non-CVS embolic event 1, cardiac tamponade 1, distal leg ischaemia 2

Dialysis-dependent

- Not reported. The outcome stated was renal dysfunction (MCS: 4; IABP 3)

Length of hospital stay

- Not reported

Length of ICU stay

- Not reported

Major adverse events

- MCS: sepsis 4

- IABP: sepsis 5

Additional outcome notes

From the 33 randomised participants, 5 IABP and 7 MCS participants were bridged to another therapy after enrolment in study. In the MCS group, 3 participants underwent extracorporeal membrane oxygenation, 2 underwent $\mathrm{PCl}, 1$ underwent mitral valve repair; 5 of this group survived. In the IABP group, 4 participants bridged to left VAD and 1 underwent $P C I$. 3 of these participants survived $\geq 30$ days.

Identification

Sponsorship source: Cardiac Assist Inc, Pittsburgh

Country: USA and Switzerland

Setting: tertiary referral centre

Authors name: Daniel Burkhoff 
Burkhoff 2006 (Continued)

Institution: Cardiovascular Research Foundation, Orangeburg, NY, USA

Notes

\section{Risk of bias}

\begin{tabular}{|c|c|c|}
\hline Bias & Authors' judgement & Support for judgement \\
\hline $\begin{array}{l}\text { Random sequence genera- } \\
\text { tion (selection bias) }\end{array}$ & Unclear risk & $\begin{array}{l}\text { Randomisation method not stated. There was a roll-in phase where VADs were } \\
\text { inserted without randomisation in centres new to the technique. People with } \\
\text { IABP already in situ were eligible. }\end{array}$ \\
\hline $\begin{array}{l}\text { Allocation concealment } \\
\text { (selection bias) }\end{array}$ & Unclear risk & Method of allocation concealment not described. \\
\hline $\begin{array}{l}\text { Blinding of participants } \\
\text { and personnel (perfor- } \\
\text { mance bias) } \\
\text { All outcomes }\end{array}$ & Unclear risk & $\begin{array}{l}\text { Participants would have been aware of treatment method. Results were sent } \\
\text { to an independent clinical research organisation. }\end{array}$ \\
\hline $\begin{array}{l}\text { Blinding of outcome as- } \\
\text { sessment (detection bias) } \\
\text { All outcomes }\end{array}$ & Unclear risk & Data sent for external analysis very unclear which method utilised. \\
\hline $\begin{array}{l}\text { Incomplete outcome data } \\
\text { (attrition bias) } \\
\text { All outcomes }\end{array}$ & Low risk & Thorough detail of outcomes for all enrolled. \\
\hline $\begin{array}{l}\text { Selective reporting (re- } \\
\text { porting bias) }\end{array}$ & Low risk & Complete outcome data available for all cases. \\
\hline Other bias & Unclear risk & $\begin{array}{l}\text { Centres that had not utilised VAD therapy previously were allowed to utilise } \\
\text { without randomisation. Most participants already had IABP in situ but failed } \\
\text { support. }\end{array}$ \\
\hline
\end{tabular}

Ouweneel 2017

\section{Study characteristics}

Study design: RCT
Study grouping: parallel group
Total duration of study: 2 years 4 months
Number of study centres and locations: 2 centres, Academic Medical Center, Amsterdam, the Nether-
lands and Haukeland University Hospital, Bergen, Norway
Study setting: tertiary referral centre
Date of the study: 24 May 2012 to 15 September 2015
Baseline characteristics
MCS
Participants
- Age (mean): 58 (SD 9) years


Ouweneel 2017 (Continued)

- Lung function: N/A

- Smoking history: N/A

- Lactate prior to initiation (mean): 7.5 (SD 3.2) mmol/L

- Cause of cariogenic shock: STEMI

IABP

- Age (mean): 58 (SD 11) years

- Gender: 20 men; 4 women

- Lung function: N/A

- Smoking history: N/A

- Lactate prior to initiation (mean): 8.9 (SD 6.6) mmol/L

- Cause of cariogenic shock: STEMI

Inclusion criteria: AMI with ST segment elevation complicated by severe CS in the setting of immediate $\mathrm{PCl}$ (severe CS defined as systolic blood pressure $<90 \mathrm{mmHg}$ for $>30$ minutes or need for inotrope or vasopressors to maintain systolic blood pressure $>90 \mathrm{mmHg}$ ). To select a patient population in even worse condition, patients only qualified if they were mechanically ventilated before randomisation.

Exclusion criteria: severe aorto-iliac arterial disease with impeding placement of IABP or MCS; known severe cardiac aortic valvular disease; serious concomitant disease with a life expectancy < 1 year; participation in this study or any other trial within the previous 30 days; coronary artery bypass grafting within preceding week.

Pretreatment: baseline characteristics of groups were well balanced.

Number of participants randomised to intervention: 48

Number of participants lost to follow-up: 0

Number of participants analysed: 48

Interventions

MCS vs IABP

\section{Intervention characteristics}

MCS

- Type of MCS: percutaneous Impella CP (maximum output 3.7 L/minute)

- Duration from diagnosis to intervention: N/A

- Duration of treatment: N/A

- Concomitant medications: $100 \%$ received inotropes/catecholamines

- Concomitant procedures: all participants underwent primary percutaneous intervention

IABP

- Duration from diagnosis to intervention: N/A

- Duration of treatment: N/A

- Concomitant medications: $100 \%$ received inotropes/catecholamines

- Concomitant procedures: all participants underwent primary percutaneous intervention

Outcomes Survival

- 30-day survival: MCS 54\%; IABP 50\%

- 1-year survival: not available

Survival measured to: transplant: unsupported cardiac function

- Not described

Quality of life 
- Not described

Major adverse cardiovascular events: all clinical outcomes at 6 months

- Cerebrovascular accident: 1 MCS; 1 IABP

- Major vascular complication: 1 MCS; 0 IABP

- Myocardial reinfarction: $1 \mathrm{MCS} ; 2$ IABP

Dialysis-dependent

- MCS: $8 / 24$ (33\%); IABP: $7 / 24(29 \%)$

- Duration (median: MCS: 17 (25th to 75th percentile 5-29) days; IABP: 7 (25th to 75th percentile 2-9) days

Length of hospital stay

- Median: MCS: 16 (25th to 75 th percentile 3-26) days; IABP: 10 (25th to 75th percentile 6-24) days

Length of ICU stay

- Median: MCS: 7 (25th to 75 th percentile 3-16) days; IABP: 7 (25th to 75th percentile 4-10) days

Major adverse event

- Major bleeding: MCS: 8 (33\%); IABP 2 (8\%)

- Haemolysis requiring extraction of the device: MCS: 2 (8\%); IABP: $0(0 \%)$

Cause of death

- Primary cause of death in both groups was brain damage (MCS: $41 \%$ of deceased; IABP: $50 \%$ of deceased). Death due to refractory CS occurred in $29 \%$ of deceased participants (MCS: $4 / 12$; IABP: $3 / 12$ )

Additional outcome notes

Of the 24 MCS participants, 1 subsequently received Impella 5.0; 1 was already received IAVP support before randomisation (inserted before start of the primary $\mathrm{PCI}$ ) and was subsequently randomised after $\mathrm{PCl}$ to $\mathrm{MCS}$ (protocol violation); 1 did not receive MCS as the participant showed signs of recovery after randomisation prior to device therapy.

Of the 24 IABP participants, 1 subsequently received MCS and was transferred to another hospital for treatment with extracorporeal life support oxygenation; 2 participants received an alternative device, the Impella 5.0 after the IABP and 1 of those received subsequent extracorporeal life support and an LVAD at another hospital.

Setting: hospital

\section{Comments:}

Authors name: Dr José PS Henriques

Institution: Department of Intensive Care Medicine, Academic Medical Center University of Amsterdam

Email: j.p.henriques@amc.uva.nl

Address: Academic Medical Center, University of Amsterdam, AMC Heart Center, Meiberg-dreef 9, 1105 AZ Amsterdam, the Netherlands

Year: 2017 
Ouweneel 2017 (Continued) $\begin{array}{ll}\text { Notes } & \text { Randomisation and placement of MCS or IABP took place after revascularisation except for } 8 \text { partici- } \\ \text { pants in whom MCS or IABP was initiated prior to revascularisation (MCS: } 5 ; \text { IABP: } 3 \text { ). }\end{array}$

\section{Risk of bias}

\begin{tabular}{|c|c|c|}
\hline Bias & Authors' judgement & Support for judgement \\
\hline $\begin{array}{l}\text { Random sequence genera- } \\
\text { tion (selection bias) }\end{array}$ & Low risk & Allocation selection using a randomised 1:1 internet application. \\
\hline $\begin{array}{l}\text { Allocation concealment } \\
\text { (selection bias) }\end{array}$ & Low risk & $\begin{array}{l}\text { Allocation sequence adequately concealed using a randomised 1:1 Internet } \\
\text { application. }\end{array}$ \\
\hline $\begin{array}{l}\text { Blinding of participants } \\
\text { and personnel (perfor- } \\
\text { mance bias) } \\
\text { All outcomes }\end{array}$ & Unclear risk & No description of methods of blinding for participants and personnel. \\
\hline $\begin{array}{l}\text { Blinding of outcome as- } \\
\text { sessment (detection bias) } \\
\text { All outcomes }\end{array}$ & Low risk & $\begin{array}{l}\text { An independent clinical event committee adjudicated the events. Imaging } \\
\text { parameters were assessed by independent local core laboratories that were } \\
\text { blinded to the other trial data and randomisation outcome. }\end{array}$ \\
\hline $\begin{array}{l}\text { Incomplete outcome data } \\
\text { (attrition bias) } \\
\text { All outcomes }\end{array}$ & Low risk & All outcome data were complete. \\
\hline $\begin{array}{l}\text { Selective reporting (re- } \\
\text { porting bias) }\end{array}$ & Low risk & All outcome data were reported. \\
\hline Other bias & Low risk & Inherent risk of bias was minimised as much as possible. \\
\hline
\end{tabular}

\section{Seyfarth 2008}

\section{Study characteristics}

\begin{tabular}{ll}
\hline Study design: prospective RCT \\
Study grouping: parallel group \\
Date of the study: September 2004 to January 2007. \\
Number of study centres and location: 2 study centres in Germany \\
Total duration of the study: approximately 3 years \\
Study setting: tertiary referral centre \\
Baseline characteristics \\
IABP \\
- Age (median): 67 (IQR $55-80)$ years \\
- Male gender, $n$ (\%): 11 (85\%) \\
- Smoking, $n$ (\%): 7 (54\%) \\
- pH: $\mathrm{N} / \mathrm{A}$ \\
- Lactate: $\mathrm{N} / \mathrm{A}$
\end{tabular}


Seyfarth 2008 (Continued)

\section{- Cause of CS: post-AMI}

MAD

- Age (median): 65 (IQR 55-80) years

- Male gender, $n(\%): 8$ (62\%)

- Smoking, $n(\%): 8$ (62\%)

- $p H: \mathrm{N} / \mathrm{A}$

- Lactate: N/A

- Baseline lung function: N/A

- Cause of CS: post-AMI

Inclusion criteria: AMI < 48 hours, confirmed by ischaemic symptoms for $\geq 30$ minutes with elevated cardiac markers or ST-segment elevation or left bundle branch block. AMI suspected when participants were resuscitated and cardiac markers or electrocardiographic changes (or both) met criteria for AMI/ acute coronary syndrome; CS defined using both clinical and haemodynamic criteria as previously described in the SHOCK trial. Clinical criteria were hypotension (systolic blood pressure $<90 \mathrm{mmHg}$ ) and heart rate $>90$ beats/minute or need for positive inotropic drugs to maintain systolic blood pressure $>$ $90 \mathrm{mmHg}$ and end-organ hypoperfusion (cool extremities or urine output $<30 \mathrm{~mL} /$ hour) or pulmonary oedema. Haemodynamic criteria were either Cardiac Index $\leq 2.2 \mathrm{~L} /$ minute $/ \mathrm{m}^{2}$ of body surface area and PCWP $>15 \mathrm{mmHg}$ or an angiographically measured left ventricular ejection fraction $<30 \%$ and left ventricular end diastolic pressure $>20 \mathrm{mmHg}$. Onset of shock had to be within 24 hours.

Exclusion criteria: aged < 18 years; prolonged resuscitation ( $>30$ minutes); hypertrophic obstructive cardiomyopathy; definite thrombus in left ventricle; treatment with IABP; severe valvular disease or mechanical heart valve; CS caused by mechanical complications of AMI such as ventricular septal defect, acute mitral regurgitation greater than second degree or rupture of ventricle; predominant right ventricular failure or need for a right VAD; sepsis; known cerebral disease; bleeding with a need for surgical intervention pulmonary embolism; allergy to heparin or any known coagulopathy; aortic regurgitation greater than second degree; pregnancy and inclusion in another study or trial.

Pretreatment: no statistically significant differences between the study groups with respect to clinical characteristics and baseline haemodynamics.

Number of participants randomised: 26

Number of participants lost to follow-up: 0

Number of participants analysed: 26

Interventions

Intervention characteristics

MAD

- Type of MCS: Impella LP2.5

- Duration from diagnosis to intervention (median): 4.5 (IQR 3.8-13.2) hours

- Duration of treatment (median): 25 (IQR 6.0-41.0) hours

- Concomitant medications: $84 \%$ inotropic support

IABP

- Duration from diagnosis to intervention (median): 5.0 (IQR 3.3-13.0) hours

- Duration of treatment (median): 23 (IQR 14.1-34.1) hours

- Concomitant medications: $92 \%$ inotropic support

Outcomes Haemodynamic effect

- Change in Cardiac Index, which was greater in the MAD group (MAD: 0.49 (SD 0.46) L/minute/m²); IABP: 0.11 (SD 0.31) L/minute $/ \mathrm{m}^{2} ; \mathrm{P}=0.02$ ). MAP increased in the MAD group by 9.0 (SD 14) $\mathrm{mmHg}$ vs -1.2 (SD 16.2) $\mathrm{mmHg}$ in the IABP group. 


\section{Overall outcome}

- Overall survival similar in both groups with 6 participants who died in each group (54\% survived to 30 days in both groups).

Survival

- 30-day survival: MCS: 7/13 (54\%); IABP: 7/13 (54\%)

- 1-year survival: N/A

Survival measured to: transplant: unsupported cardiac function

- Not described

Quality of life

- Not described

Major adverse cardiovascular events

- Limb ischaemia: MCS: 1; IABP: 0

- Other complications: not described

Dialysis-dependent

- Not reported

Length of hospital stay

- Not reported

Length of ICU stay

- Not reported

Major adverse events

- Not reported

Identification

Sponsorship source: Abiomed Europe Gmb

Country: Germany

Setting: 2 centres

Comments:

Authors name: Melchior Seyfarth

Institution: Deutsches Herzzentrum München

Email: seyfarth@dhm.mhn.de

Address: Deutsches Herzzentrum München, Lazarettstrasse 36, 80636 Munich, Germany

Year: 2008

Notes Interventions

The assigned device was implanted after revascularisation therapy and following the measurement of baseline haemodynamic parameters.

\section{Risk of bias}


Seyfarth 2008 (Continued)
Random sequence genera- Unclear risk
Stated the participants were randomly allocated to either device, but the tion (selection bias) method of allocation not described.

Allocation concealment
(selection bias)

Blinding of participants Unclear risk Unable to blind participants and personnel.
and personnel (perfor-
mance bias)
All outcomes

\begin{tabular}{lll}
\hline $\begin{array}{l}\text { Blinding of outcome as- } \\
\text { sessment (detection bias) } \\
\text { All outcomes }\end{array}$ & Unclear risk & No description of whether the outcome assessment was blinded or not. \\
\hline $\begin{array}{l}\text { Incomplete outcome data } \\
\text { (attrition bias) } \\
\text { All outcomes }\end{array}$ & Low risk & No loss of follow-up. \\
\hline $\begin{array}{l}\text { Selective reporting (re- } \\
\text { porting bias) }\end{array}$ & Low risk & Complete description of outcome data. \\
\hline Other bias & Unclear risk & Unclear throughout the paper how they dealt with the risk of bias.
\end{tabular}

\section{Thiele 2005}

\section{Study characteristics}

Study design: RCT

Study grouping: parallel group

Date of study: August 2000 to December 2003

\section{Number of study centres: 1}

Study setting: Department of Internal Medicine/Cardiology, University of Leipzig-Heart Centre, Strumpellstr. 39, 04289 Leipzig, Germany

Total duration of the study: 3 years and 5 months

\section{Baseline characteristics}

TandemHeart VAD

- Age (median): 63 (IQR 57-70) years

- Male gender, $n(\%): 16$ (76)

- Diabetes, $n(\%): 11$ (52)

- Smoking, $n(\%): 9$ (43)

- $p H$ (median): 7.28 (IQR 7.24-7.36)

- Lactate prior to intervention (median): 4.5 (3.1-6.5)

- Lung function: not documented

- Cause of CS: AMI

IABP

- Age (median): 65 (IQR 59-73) years 
Thiele 2005 (Continued)

- Male gender, $n(\%): 15$ (75)

- Diabetes, $n(\%): 11$ (55)

- Smoking, $n(\%): 6(30)$

- $p H$ (median): 7.34 (IQR 7.28-7.38)

- Lactate prior to intervention (median): 3.8 (3.5-6.7)

- Lung function: not documented

- Cause of CS: AMI

Baseline clinical characteristics were similar for both groups.

Baseline haemodynamic characteristics were similar for both groups except for a higher PCWP in the IABP group (MCS (median): 20.0 (IQR 18-23); IABP 27 (IQR 20-30); P = 0.02).

Inclusion criteria: he presence of CS complicating AMI and intention to revascularise the infarcted artery by $\mathrm{PCl}$ as first-line treatment option. CS identified as: persistent systolic blood pressure $<90$ $\mathrm{mmHg}$ or vasopressors required to maintain blood pressure $>90 \mathrm{mmHg}$; evidence of end organ failure (e.g. urine output $<30 \mathrm{~mL} /$ hour, cold skin and extremities, and serum lactate $>2 \mathrm{mmol} / \mathrm{L}$ ); evidence of elevated left ventricular filling pressures (pulmonary congestion or PCWP > $15 \mathrm{mmHg}$ ); and Cardiac In$\operatorname{dex}>2.1 \mathrm{~L} / \mathrm{min} / \mathrm{m}^{2}$.

Exclusion criteria: aged > 75 years; mechanical complications of AMI; duration of CS > 12 hours; right heart failure; sepsis; significant aortic regurgitation; severe cerebral damage; resuscitation $>30$ minutes; severe peripheral vascular disease and other diseases with reduced life expectancy.

\section{Number of participants analysed: 41}

\section{Number of participants lost to follow-up: 0}

1 participant did not receive the MAD as the patient showed rapid haemodynamic improvement after $\mathrm{PCl}$ but was included in the final analysis according to intention-to-treat principles.

Number of participants randomised to intervention: 41

- Type of MCS: TandemHeart VAD; after transeptal puncture a venous inflow cannula was inserted into left atrium. Oxygenated blood was drawn and returned via a centrifugal pump and an arterial cannula in the femoral artery to the lower abdominal aorta. To avoid limb ischaemia in smaller participants, 2 arterial cannulae of 12 -French in both femoral arteries were recommended. System was capable of delivering flow up to $4.0 \mathrm{~L} /$ minute at $7500 \mathrm{rpm}$ but the 12 -French cannula limited flow to $3.0 \mathrm{~L} / \mathrm{minute}$.

- Duration (diagnosis to intervention) (median): 11.0 (IQR 6.8-18.80) minutes

- Duration of treatment (median): 3.5 (IQR 2.0-4.5) days

- Inotropes or vasopressors (median): 3.0 (IQR 1.0-3.0) days

IABP

- Type of IABP: Datascope Corporation IABP inserted percutaneously, heparin administered intravenously and all participants were initially on a pumping ratio of $1: 1$ with $100 \%$ balloon inflation.

- Duration (diagnosis to intervention) (median): 10.0 (IQR 5.3-25.5) minutes

- Duration of treatment (median): 4.0 (IQR 3.5-4.0) days

- Inotropes or vasopressors (median): 2.0 (IQR 1.0-4.0) days

- CPI improved by MCS from 0.22 (IQR $0.19-0.30) \mathrm{W} / \mathrm{m}^{2}$ to 0.37 (IQR $\left.0.30-0.47\right) \mathrm{W} / \mathrm{m}^{2}(\mathrm{P}<0.001)$ when compared with IABP (from 0.22 (IQR 0.18-0.30) W/m² to 0.28 (IQR $0.24-0.36) \mathrm{W} / \mathrm{m}^{2} ; \mathrm{P}=0.02 ; \mathrm{P}=0.004$ for intergroup comparison). Time of first CPI measurement after device implantation was similar (MCS: 40.0 (IQR 25.5-53.5) minutes; IABP: 33.5 (IQR 19.0-50.5) minutes; $\mathrm{P}=0.28$ ). 
Thiele 2005 (Continued)

\section{Overall outcomes}

Survival

- 30-day survival: MCS: 57\% survival; IABP: 55\% survival

Survival measured to: transplant: unsupported cardiac function

- Not described

Quality of life

- Not reported

Major adverse cardiovascular events

- In the MCS group, 7 participants developed limb ischaemia after implantation of a 17-French arterial cannula and 0 in the IABP group $(P=0.009)$.

Dialysis-dependent

- Not reported

Length of hospital stay

- Not reported

Length of ICU stay

- Not reported

Major adverse events

- 13 participants in the MCS group and 3 in the IABP group had signs of DIC. In 8 MCS participants, DIC was severe with subsequent haemorrhagic diathesis. In 3 IABP participants, DIC was mild and could be resolved by substitution with antithrombin III.

Country: Germany

Setting: Department of Internal Medicine/Cardiology, University of Leipzig-Heart Centre, Germany

\section{Comments:}

Authors names: Holger Thiele*, Peter Sick, Enno Boudriot, Klaus-Werner Diederich, Rainer Hambrecht, Josef Niebauer, and Gerhard Schule

Institution: Department of Internal Medicine/Cardiology, University of Leipzig-Heart Centre

Email: thielh@medizin.uni-leipzig.de

Address: Department of Internal Medicine/Cardiology, University of Leipzig-Heart Centre, Strümpellstraße 39, 04289 Leipzig, Germany

\section{Outcomes}

Cause of death: 4 participants in each group 3 in IABP due to LHF in the first 2 hours then 1 within 24 hours of $\mathrm{PCI}$ due to MODS. In the MCS group, 0 died within the 24 hours. However, 4 participants died between days 2 and 4 as a cause of MODS despite active circulatory support. 5 additional participants died in each group after weaning during 30-day follow-up, resulting in an overall mortality of $45 \%$ in the IABP group and $43 \%$ in the MCS group (log-rank, $P=0.86$ ). In the MCS group, 3 participants died after weaning due to recurrent LHF, and 2 due to sepsis or MODS. The cause of death after IABP explantation was MODS in 3 and acute LHF in 2 participants. There were no 30-day mortality differences for par- 
Thiele 2005 (Continued)

ticipants with pre-PCl assist support (MCS: 44\%; IABP: 56\%) and for those with post-PCI support (MCS: 42\%; IABP: 36\%).

\begin{tabular}{|c|c|c|}
\hline \multicolumn{3}{|l|}{ Risk of bias } \\
\hline Bias & Authors' judgement & Support for judgement \\
\hline $\begin{array}{l}\text { Random sequence genera- } \\
\text { tion (selection bias) }\end{array}$ & Low risk & Randomised by drawing sealed envelopes. \\
\hline $\begin{array}{l}\text { Allocation concealment } \\
\text { (selection bias) }\end{array}$ & Low risk & $\begin{array}{l}\text { Study specified that some appropriate safeguards were taken, i.e. sealed en- } \\
\text { velopes, but did not mention if they were non-opaque or not sequentially } \\
\text { numbered. }\end{array}$ \\
\hline $\begin{array}{l}\text { Blinding of participants } \\
\text { and personnel (perfor- } \\
\text { mance bias) } \\
\text { All outcomes }\end{array}$ & Unclear risk & $\begin{array}{l}\text { Study did not describe whether the participants and personnel were blinded } \\
\text { or not. }\end{array}$ \\
\hline $\begin{array}{l}\text { Blinding of outcome as- } \\
\text { sessment (detection bias) } \\
\text { All outcomes }\end{array}$ & Unclear risk & No blinding of outcomes assessors described. \\
\hline $\begin{array}{l}\text { Incomplete outcome data } \\
\text { (attrition bias) } \\
\text { All outcomes }\end{array}$ & Low risk & No missing data outcomes \\
\hline $\begin{array}{l}\text { Selective reporting (re- } \\
\text { porting bias) }\end{array}$ & Low risk & $\begin{array}{l}\text { All of the study's prespecified (primary and secondary) outcomes that were of } \\
\text { interest in the review were reported in the prespecified way. }\end{array}$ \\
\hline Other bias & Low risk & Inherent risk of bias was minimised as much as possible. \\
\hline
\end{tabular}

See Appendix 2 for a glossary of terms.

AMI: acute myocardial infarction; CS: cardiogenic shock; CPI: Cardiac Power Index; CVS: cardiovascular system; DIC: disseminated intravascular coagulation; IABP: intra-aortic balloon pump; IAVP: implantable aortic valvo-pump; ICU: intensive care unit; IQR: interquartile range; LHF: left heart failure; MAD: mechanical assist device; MAP: mean arterial blood pressure; MCS: mechanical circulatory support; MODS: multiorgan dysfunction syndrome; N/A: not applicable; PCI: percutaneous coronary intervention; PCWP: pulmonary capillary wedge pressure; pMCS: percutaneous mechanical circulatory support; pVAD: percutaneous ventricular assist device; RCT: randomised controlled trial; rpm: revolutions per minute; SD: standard deviation; STEMI: ST elevation myocardial infarction; VAD: ventricular assist device.

Characteristics of excluded studies [ordered by study ID]

\begin{tabular}{ll}
\hline Study & Reason for exclusion \\
\hline Abraham 2012 & Ineligible cohort - end-stage chronic heart failure not acute cardiogenic shock. \\
\hline Abraham 2014 & Ineligible cohort - end-stage chronic heart failure. \\
\hline Agarwal 2015 & Registry data - not an RCT. \\
\hline Agrawal 2016 & Review article - with no new RCT data for the relevant cohort. \\
\hline Almond 2017 & Ineligible cohort. \\
\hline Alushi 2019 & Cohort study - no RCT data. \\
\hline
\end{tabular}




\begin{tabular}{|c|c|}
\hline Study & Reason for exclusion \\
\hline Anderson 2006 & Meeting abstract - registry data. \\
\hline Basir 2019 & Cohort study - no RCT data. \\
\hline Birks 2009 & Ineligible cohort. \\
\hline Birks 2018 & Prospective cohort study - end-stage heart failure. \\
\hline Bluhm 2010 & Prospective non-randomised trial. \\
\hline Bol 2019 & Ineligible cohort. \\
\hline Bronicki 2013 & Ineligible cohort chronic heart failure. \\
\hline Brunner 2019 & Letter with no reference to any additional RCT data. \\
\hline Kar 2012 & Review article - no additional RCT data. \\
\hline Liu 2012 & Non-randomised trial. \\
\hline Morici 2018 & Cohort study - no RCT data. \\
\hline NCT03101787 & Registered clinical trial - ineligible treatment in an ineligible cohort. \\
\hline NCT03431467 & Registered clinical trial - ineligible control group. \\
\hline Patel 2011 & Ineligible cohort - high-risk PCI not cardiogenic shock. \\
\hline Saeed 2013 & Ineligible cohort - chronic heart failure. \\
\hline Vallabhajosyula 2017 & Review article - with no new RCT data for the relevant cohort. \\
\hline
\end{tabular}

PCI: percutaneous coronary intervention; RCT: randomised controlled trial.

\section{Characteristics of ongoing studies [ordered by study ID]}

DanGer Shock Trial

\begin{tabular}{ll}
\hline Study name & DanGer shock \\
\hline Methods & $\begin{array}{l}\text { Prospective randomised (1:1), multicentre, open-label trial in people with STEMI complicated by } \\
\text { cardiogenic shock }\end{array}$ \\
\hline Participants & $\begin{array}{l}\text { 360 people with acute myocardial infarction cardiogenic shock undergoing primary percutaneous } \\
\text { coronary intervention for STEMI. }\end{array}$ \\
\hline Interventions & Percutaneous Impella CP 3.8L with the device implanted before revascularisation \\
\hline Outcomes & Primary outcomes \\
- Death (follow-up 6 months) & Death from all causes \\
Secondary outcomes \\
- MACE (timeframe 6 months)
\end{tabular}


- Major cardiovascular events, death, cardiac transplant, escalation to permanent left ventricular assist device, rehospitalisation with heart failure.

- Combined safety (timeframe 6 months)

- Combined safety comprising major bleeding, vascular complications and significant haemolysis.

- Renal function (timeframe 6 months)

- Glomerular filtration rate, use dialysis

- SIRS (timeframe 1 month)

- Development of SIRS

- Health economics (timeframe 6 months)

- Cost of treatments

- Haemodynamics (timeframe 7 days)

- Cardiac Power Index, lactate clearance, pulmonary capillary wedge pressure

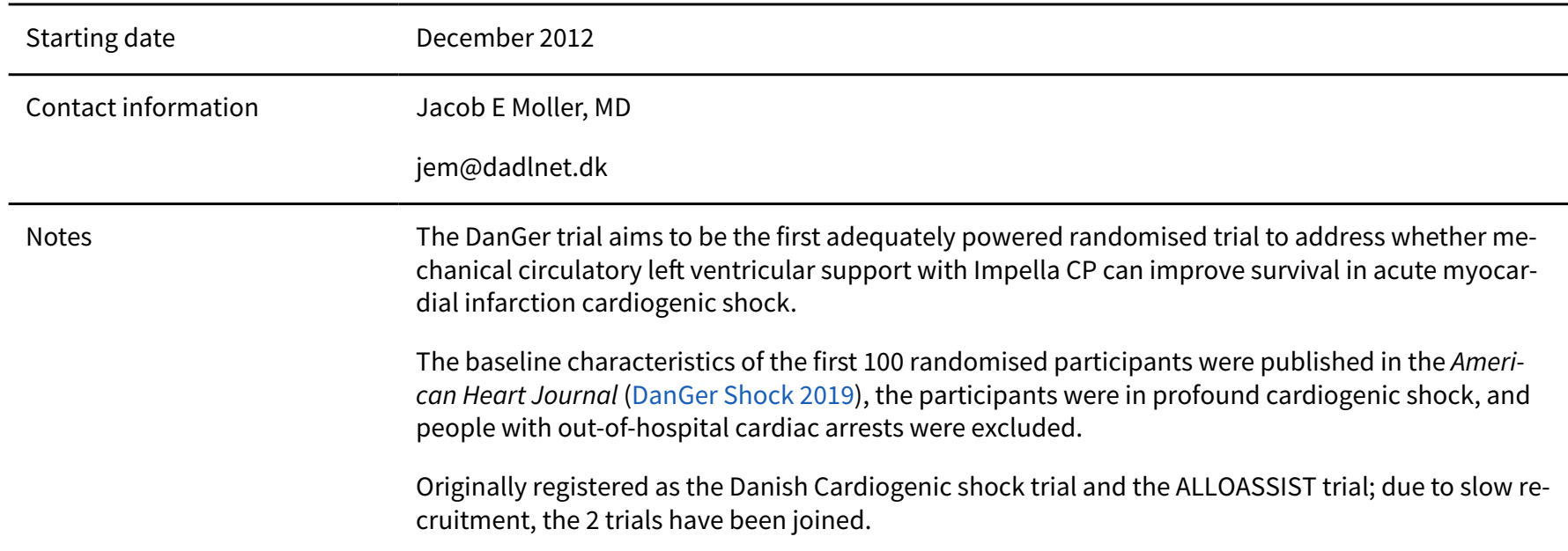

\section{ECLS-SHOCK}

\begin{tabular}{|c|c|}
\hline Study name & $\begin{array}{l}\text { Clinical study of extra-corporal life support in cardiogenic shock complicating acute myocardial in- } \\
\text { farction }\end{array}$ \\
\hline Methods & $\begin{array}{l}\text { Randomised controlled trial studying standard treatment + ECLS vs standard treatment alone in } \\
\text { people with cardiogenic shock due to myocardial infarction. }\end{array}$ \\
\hline Participants & People with cardiogenic shock complicating acute myocardial infarction STEMI/non-STEMI \\
\hline Interventions & ECLS from Sorin \\
\hline Outcomes & $\begin{array}{l}\text { Primary outcome } \\
\text { - LVEF on day } 30 \text { (timeframe } 30 \text { days) } \\
\text { Secondary outcomes } \\
\text { - } 30 \text {-day mortality (timeframe } 30 \text { days) } \\
\text { - Lactate levels (timeframe up to } 48 \text { hours) } \\
\text { - Length of mechanical ventilation (timeframe } 30 \text { days) } \\
\text { - Long-term mortality at } 6 \text { and } 12 \text { months (timeframe up to } 12 \text { months) } \\
\text { - LVEF after } 6 \text { and } 12 \text { months (timeframe up to } 12 \text { months) } \\
\text { - Length of ICU stay (timeframe } 30 \text { days) } \\
\text { - Quality of life on day } 30 \text {, after } 6 \text { and } 12 \text { months (timeframe up to } 12 \text { months) }\end{array}$ \\
\hline
\end{tabular}


- 6-minute walk distance on day 30, after 6 and 12 months (timeframe up to 12 months)

- New York Heart Association classification on day 30, after 6 and 12 months (timeframe up to 12 months)

\begin{tabular}{ll}
\hline Starting date & September 2015 \\
\hline Contact information & Stefan Brunner, MD \\
\hline
\end{tabular}

\section{Notes}

\section{ECMO-CS}

\begin{tabular}{ll}
\hline Study name & Extracorporeal membrane oxygenation in the therapy of cardiogenic shock (ECMO-CS) \\
\hline Methods & Randomised controlled trial \\
\hline Participants & Adults with acute cardiogenic shock \\
\hline Interventions & Immediate venoarterial ECMO \\
\hline Outcomes & Primary outcome \\
& - Composite of death from any cause, resuscitated circulatory arrest and implantation of another \\
& mechanical circulatory support device (timeframe: 30 days) \\
Secondary outcomes & All-cause mortality (timeframe: 30 days) \\
- All-cause mortality (timeframe: 6 months) \\
- All-cause mortality (timeframe: 12 months) \\
Neurological outcome (according to Cerebral Performance Category scale) (timeframe: 30 days)
\end{tabular}

\begin{tabular}{ll}
\hline Starting date & 26 November 2014 \\
\hline Contact information & Petr Ostadal, MD, PhD; ostadal.petr@gmail.com
\end{tabular}

Notes

\section{EuroShock}

Study name Testing the value to novel strategy and its cost efficacy in order to improve the poor outcomes in
cardiogenic shock (EUROSHOCK)

\begin{tabular}{ll}
\hline Methods & Multicentre randomised controlled trial \\
\hline Participants & Adults with acute cardiogenic shock following acute coronary syndrome \\
\hline Interventions & Venoarterial ECMO \\
\hline Outcomes & Primary outcomes \\
& All-cause mortality (timeframe: at 30 days) \\
& Death from any cause \\
\hline
\end{tabular}


EuroShock (Continued)

\section{Secondary outcomes}

- All-cause mortality or admission for heart failure (timeframe: at 12 months)

- Death from any cause, or admission to hospital for heart failure with typical symptoms (e.g. breathlessness, ankle swelling and fatigue) that may be accompanied by signs (e.g. elevated jugular venous pressure, pulmonary crackles and peripheral oedema) caused by a structural or functional (or both) cardiac abnormality, resulting in a reduced cardiac output or elevated intracardiac pressures (or both) at rest or during stress.

- All-cause mortality (timeframe: at 12 months)

- Death from any cause

- Admission for heart failure (timeframe: at 12 months)

- Admission to hospital with clinical syndrome of heart failure, defined as per the European Society of Cardiology guidelines as typical symptoms (e.g. breathlessness, ankle swelling and fatigue) that may be accompanied by signs (e.g. elevated jugular venous pressure, pulmonary crackles and peripheral oedema) caused by a structural or functional (or both) cardiac abnormality, resulting in a reduced cardiac output or elevated intracardiac pressures (or both) at rest or during stress.

\begin{tabular}{ll}
\hline Starting date & January 2019 \\
\hline Contact information & Anthony H Gershlick; ahg8@le.ac.uk \\
\hline Notes & \\
\hline
\end{tabular}

ECLS: extracorporeal life support; ECMO: extracorporeal membrane oxygenation; ICU: intensive care unit; LVEF: left ventricular ejection fraction; MACE: major adverse cardiovascular event; SIRS: systemic inflammatory response syndrome; STEMI: ST elevation myocardial infarction.

\section{DATA AND ANALYSES}

\section{Comparison 1. Mechanical circulatory support (MCS) versus intra-aortic balloon pump (IABP)}

\begin{tabular}{lllll}
\hline Outcome or subgroup title & $\begin{array}{l}\text { No. of } \\
\text { studies }\end{array}$ & $\begin{array}{l}\text { No. of } \\
\text { partici- } \\
\text { pants }\end{array}$ & Statistical method & Effect size \\
\hline 1.1 30-day survival & 5 & 162 & Risk Ratio (M-H, Random, 95\% Cl) & $1.01[0.76,1.35]$ \\
\hline 1.1 .1 TandemHeart device & 2 & 75 & Risk Ratio (M-H, Random, 95\% Cl) & $0.95[0.64,1.42]$ \\
\hline 1.1 .2 Other device & 3 & 87 & Risk Ratio (M-H, Random, $95 \% \mathrm{Cl})$ & $1.09[0.71,1.66]$ \\
\hline
\end{tabular}


Analysis 1.1. Comparison 1: Mechanical circulatory support (MCS) versus intra-aortic balloon pump (IABP), Outcome 1: 30-day survival

\begin{tabular}{|c|c|c|c|c|c|c|}
\hline & Mechanical assist device (MAD) & & & & Risk Ratio & Risk Ratio \\
\hline Study or Subgroup & Events & Events & Total & Weight & M-H, Random, 95\% CI & M-H, Random, 95\% CI \\
\hline
\end{tabular}

\subsubsection{TandemHeart device}

Burkhoff 2006

Thiele 2005

Subtotal (95\% CI)

$10 \quad 19$

12

19
21

Heterogeneity: $\mathrm{Tau}^{2}=0.00 ; \mathrm{Chi}^{2}=0.50, \mathrm{df}=1(\mathrm{P}=0.48) ; \mathrm{I}^{2}=0 \%$

Test for overall effect: $\mathrm{Z}=0.24(\mathrm{P}=0.81)$

\subsubsection{Other device}

Seyfarth 2008 (1)

Ouweneel 2017 (2)

Bonnefoy-Cudraz 2014 (3)

Subtotal (95\% CI)

Total events:

12

9

$11 \quad 21 \quad 28.0 \%$

$35 \quad \mathbf{5 3 . 4 \%}$

$0.82[0.46,1.46]$

$1.09[0.63,1.89]$

20

$0.95[0.64,1.42]$

Heterogeneity: $\mathrm{Tau}^{2}=0.00 ; \mathrm{Chi}^{2}=1.02, \mathrm{df}=2(\mathrm{P}=0.60) ; \mathrm{I}^{2}=0 \%$

Test for overall effect: $\mathrm{Z}=0.38(\mathrm{P}=0.71)$

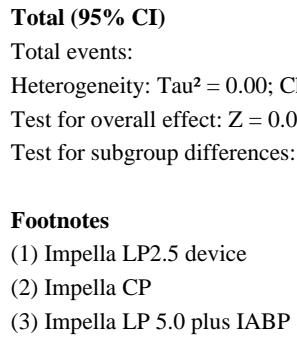

84

13
24
7
44

$\begin{array}{lll}7 & 13 & 16.8 \%\end{array}$

$12 \quad 24 \quad 28.8 \%$

$0 \quad 6 \quad 1.0 \%$

$43 \quad 46.6 \%$

$78 \quad \mathbf{1 0 0 . 0} \%$
$1.00[0.49,2.04]$

$1.08[0.63,1.87]$

$4.38[0.25,76.54]$

$1.09[0.71,1.66]$

-H, Random, 95\% CI

\section{AP PEN DICES}

\section{Appendix 1. Glossary}

Acute cardiac failure: sudden loss of heart function.

Acute myopericarditis: sudden inflammation of the heart muscle or the lining of the heart.

Cardiogenic shock: develops when the heart muscle has been damaged so extensively it can no longer pump enough blood to maintain the bodies function and if not reversed will lead to organ damage and death.

Continuous flow: the pressure in the person's arterial system is continuous and does not change and the person does not have a palpable pulse.

Haemodynamic support: medical help to maintain the blood supply to vital organs.

Heart failure: the heart is unable to effectively pump blood around the body.

Intracorporeal ventricular assist device: is a pumping device which is situated inside the body that assists the heart to pump blood.

Left/right ventricular end diastolic pressure: the pressure in the left/right ventricle when the heart is at rest prior to contracting.

Myocardial infarction: heart attack.

Organ hypoperfusion: is a state where the organs are not receiving enough blood to receive adequate oxygen and nutrients to function/ stay alive.

Paracorporeal ventricular assist device: is a pumping device which is situated outside the body which is connected to the major blood vessels to assist the heart to pump blood.

Percutaneous device: is a device that is inserted via a needle through the skin into a blood vessel. 
Peripartum cardiomyopathy: when a woman's heart muscle does not function well around the time of childbirth.

Persistent hypotension: continuous low blood pressure.

Postcardiotomy cardiogenic shock: where a person's heart is able to pump after open heart surgery.

Pulsatile flow: blood flow which has a variable pressure and the person has a pulse.

Refractory cardiogenic shock: the heart is no longer pumping adequately despite the maximum medical treatment.

ST elevation myocardial infarction: serious heart attack leading to heart muscle death.

Surgical device: is a device that is inserted via opening the body using a scalpel.

Takotsubo cardiomyopathy: broken heart syndrome, where the heart becomes suddenly weakened.

Univentricular/biventricular dysfunction: the heart has two pumping chambers, right and left ventricle. If one is not working properly this is univentricular dysfunction; if both are not working properly it is biventricular dysfunction.

Vasopressor/inotropic support: medications that increase blood pressure by helping the heart to pump stronger and faster.

\section{Appendix 2. Search strategies}

\section{CENTRAL}

\#1MeSH descriptor: [Heart Failure] explode all trees

\#2((heart or cardiac or myocardial) near/2 fail ${ }^{*}$ )

\#3MeSH descriptor: [Shock, Cardiogenic] this term only

$\# 4$ (Cardiogenic near/2 shock)

\#5\#1 or \#2 or \#3 or \#4

\#6MeSH descriptor: [Heart-Assist Devices] this term only

$\# 7\left((\text { mechanical or heart) near/2 (assist or device })^{\star}\right)$

\#8((ventric ${ }^{\star}$ or biventric $\left.{ }^{\star}\right)$ near/2 assist $\left.^{\star}\right)$

\#9((ventric ${ }^{\star}$ or biventric $\left.{ }^{\star}\right)$ near/2 device*)

$\# 10$ (VAD or VADs or LVAD or LVADs or RVAD or RVADs or BIVAD or BIVADs)

$\# 11 \mathrm{MeSH}$ descriptor: [Extracorporeal Membrane Oxygenation] this term only

\#12ECMO

\#13(extracorporeal near/3 membrane)

\#14(extracorporeal near/3 mechanical)

\#15(extracorporeal near/3 life support)

\#16ECLS

\#17ELS

$\# 18 \# 6$ or \#7 or \#8 or \#9 or \#10 or \#11 or \#12 or \#13 or \#14 or \#15 or \#16 or \#17

$\# 19 \# 5$ and \#18

\section{MEDLINE Ovid}

1 exp Heart Failure/

2 ((heart or cardiac or myocardial) adj2 fail $\left.{ }^{\star}\right)$.tw.

3 Shock, Cardiogenic/

4 (Cardiogenic adj2 shock).tw.

51 or 2 or 3 or 4

6 Heart-Assist Devices/

7 ((mechanical or heart) adj2 (assist or device*)).tw.

8 ((ventric ${ }^{\star}$ or biventric $\left.{ }^{\star}\right)$ adj2 assist $\left.^{\star}\right)$.tw.

9 ((ventric ${ }^{\star}$ or biventric $\left.{ }^{\star}\right)$ adj2 device $\left.{ }^{\star}\right)$.tw.

10 (VAD or VADs or LVAD or LVADs or RVAD or RVADs or BIVAD or BIVADs).tw.

11 Extracorporeal Membrane Oxygenation/

12 ECMO.tw.

13 (extracorporeal adj3 membrane).tw.

14 (extracorporeal adj3 mechanical).tw.

15 (extracorporeal adj3 life support).tw.

16 ECLS.tw.

17 ELS.tw.

186 or 7 or 8 or 9 or 10 or 11 or 12 or 13 or 14 or 15 or 16 or 17

195 and 18 
20 randomized controlled trial.pt.

21 controlled clinical trial.pt.

22 randomized.ab.

23 placebo.ab.

24 drug therapy.fs.

25 randomly.ab.

26 groups.ab.

2720 or 21 or 22 or 23 or 24 or 25 or 26

28 exp animals/ not humans.sh.

2927 not 28

3019 and 29

\section{Embase Ovid}

1 exp heart failure/ (423396)

2 ((heart or cardiac or myocardial) adj2 fail $\left.{ }^{\star}\right)$.tw.

3 cardiogenic shock/

4 (Cardiogenic adj2 shock).tw.

51 or 2 or 3 or 4

6 heart assist device/

7 ((mechanical or heart) adj2 (assist or device $\left.\left.{ }^{\star}\right)\right)$. tw.

8 ((ventric ${ }^{\star}$ or biventric $\left.{ }^{\star}\right)$ adj2 assist $\left.{ }^{\star}\right)$.tw.

9 ((ventric ${ }^{\star}$ or biventric $\left.{ }^{\star}\right)$ adj2 device $\left.{ }^{\star}\right)$.tw.

10 (VAD or VADs or LVAD or LVADs or RVAD or RVADs or BIVAD or BIVADs).tw.

11 extracorporeal oxygenation/

12 ECMO.tw.

13 (extracorporeal adj3 membrane).tw.

14 (extracorporeal adj3 mechanical).tw.

15 (extracorporeal adj3 life support).tw.

16 ECLS.tw.

17 ELS.tw.

186 or 7 or 8 or 9 or 10 or 11 or 12 or 13 or 14 or 15 or 16 or 17

195 and 18

20 random $\$$.tw.

21 factorial\$.tw.

22 crossover\$.tw.

23 cross over $\$$.tw.

24 cross-over $\$$.tw.

25 placebo\$.tw.

26 (doubl\$ adj blind\$).tw.

27 (singl\$ adj blind\$).tw.

28 assign\$.tw.

29 allocat\$.tw.

30 volunteer $\$$.tw.

31 crossover procedure/

32 double blind procedure/

33 randomized controlled trial/

34 single blind procedure/

3520 or 21 or 22 or 23 or 24 or 25 or 26 or 27 or 28 or 29 or 30 or 31 or 32 or 33 or 34

36 (animal/ or nonhuman/) not human/

3735 not 36

3819 and 37

\section{Web of Science}

\# 17 \#16 AND \#15

\# 16 TS=(random ${ }^{\star}$ or blind ${ }^{\star}$ or allocat ${ }^{\star}$ or assign* or trial* or placebo* or crossover ${ }^{\star}$ or cross-over $\left.^{\star}\right)$

\# 15 \#14 AND \#3

\# 14 \#13 OR \#12 OR \#11 OR \#10 OR \#9 OR \#8 OR \#7 OR \#6 OR \#5 OR \#4

$\# 13$ TS=ELS

\# 12 TS=ECLS

\# 11 TS=(extracorporeal near/3 life support)

\# 10 TS=(extracorporeal near/3 mechanical)

\# 9 TS=(extracorporeal near/3 membrane)

Mechanical assist devices for acute cardiogenic shock (Review) 
\# 8 TS=ECMO

\# 7 TS=(VAD or VADs or LVAD or LVADs or RVAD or RVADs or BIVAD or BIVADS)

\# $6 \mathrm{TS}=\left(\left(\right.\right.$ ventric $^{\star}$ or biventric $\left.{ }^{\star}\right)$ near $/ 2$ device $\left.{ }^{\star}\right)$

\# 5 TS $=\left(\left(\right.\right.$ ventric $^{*}$ or biventric $\left.{ }^{\star}\right)$ near $/ 2$ assist $\left.^{\star}\right)$

\# 4 TS= $=\left(\right.$ mechanical or heart) near/2 (assist or device $\left.\left.{ }^{\star}\right)\right)$

\# 3 \#2 OR \#1

\# 2 TS=(Cardiogenic near/2 shock)

\# 1 TS=((heart or cardiac or myocardial) near $/ 2$ fail $\left.{ }^{\star}\right)$

\section{Clinical Trial registers and other resources}

\#1 Cardiogenic shock

\section{H IS T O R Y}

Protocol first published: Issue 4, 2018

Review first published: Issue 6, 2020

\section{CONTRIBUTIONS OF AUTHORS}

TNH: with JS independently screened titles and abstracts for inclusion of potential studies. Wrote the first draft of the results, reviewed and revised the discussion, and inputted the data into the 'Characteristics of studies' tables and made amendments to revise the paper as per editors' comments.

HB: reviewed the draft of the results and wrote the first draft of the discussion.

KB: reviewed the selected papers and was available for advice regarding any conflicts; reviewed and added data from the included papers into Covidence; reviewed the final paper.

JS: with TNH independently screened the abstracts and titles. Independent of TNH performed risk of bias in the included studies; and added paragraphs to discussion section and reviewed the results.

CC: independent to TNH and JS screened titles and abstracts for inclusion of all potential papers. Inputted data from the included studies into the 'Summary of findings' table.

OB: reviewed the results and the statistical data from the paper.

SW: reviewed the final draft of the completed paper.

\section{DECLARATIONS OF INTEREST}

TNH: none.

HB: none.

KB: none.

JS: none.

CC: none.

OB: I have not received any payment (or benefits), either directly or indirectly, for my contribution to (or as a consequence of my involvement in) this project.

SW: Professor Westaby is medical director of Cell Therapy Ltd, and founder and shareholder of Calon Cardiotechnology.

\section{SOURCES OF SUPPORT}

\section{Internal sources}

- No sources of support supplied 


\section{External sources}

- NIHR Infrastructure funding, UK

This project was supported by the National Institute for Health Research (NIHR), via Cochrane Infrastructure funding to the Heart Group. The views and opinions expressed therein are those of the authors and do not necessarily reflect those of the Systematic Reviews Programme, NIHR, National Health Service (NHS) or the Department of Health and Social Care

\section{DIFFERENCES BETWEEN PROTOCOLANDREVIEW}

We planned to study survival at 30 days, one year, end of follow-up, to transplantation or unsupported cardiac care. However, the only survival data available was for 30 days.

We planned to report on outcomes such as overall survival, survival to transplant, survival to unsupported cardiac function and major adverse events where possible. We reported confidence intervals $(\mathrm{Cl})$ of time to death and time to major adverse events, along with point estimates. We planned to describe dichotomous data relating to status at a fixed time point using risk ratios (RRs) with corresponding $\mathrm{Cl}$ (Higgins 2011). For continuous outcomes, we calculated the mean difference (MD) between the treatment arms at the end of follow-up, if all trials measured the outcome on the same scale, otherwise we planned to pool standardised mean differences (SMDs). However, these data were not provided in the studies.

We planned to carry out the following subgroup analyses.

1. Neonatal (less than 28 days of age)/paediatric (28 days to 16 years of age)/adult (greater than 16 years of age).

2. Cause of acute cardiogenic shock/ischaemic heart disease/cardiomyopathy/acute myopericarditis.

3. Mechanical assist device (MAD) compared with intra-aortic balloon pump (IABP).

4. MAD compared with best medical therapy excluding IABP.

5. pMADs (using Seldinger insertion technique) versus surgical MADs (inserted via sternotomy/thoracotomy).

6. Long-term MCS devices (durable left ventricular assist device) compared with short-term MCS devices (for example, extracorporeal membrane oxygenation, Impella).

7. Participants who had refractory cardiac arrest compared with participants with no cardiac arrest at the time of device implantation.

However, there were insufficient data to do these analyses.

We planned to do an economic commentary, but there were insufficient published data to do so. 